\title{
The role of process control on the steel cleanliness
}

\author{
K. Steneholm*, Nils Å.I. Andersson**, A. Tilliander** and P.G. Jönsson** \\ * Uddeholms AB, SE-683 85 Hagfors, Sweden. \\ **Div. of Processes, KTH-Royal Institute of Technology, SE-100 44 Stockholm, Sweden
}

\begin{abstract}
The possibilities of obtaining a good process control in order to reach a good cleanliness of the steel were studied based on plant trials. Steel and slag samples were taken from two steel grades with a slightly different composition, but with similar processing conditions. Thereafter, the chemical compositions of the steel and slag samples were determined. The results show that the sum of the $\mathrm{FeO}$ and $\mathrm{MnO}$ was found to be a clear indicator for when reoxidation had taken place. No conclusive indicator was found to predict the extent of slag carry-over from the electric arc furnace. However, most of the variation in deoxidation seem to originate from the accuracy of the slag raking. Steel grades with low amounts of deoxidisers such as $\mathrm{C}$ and $\mathrm{Si}$ naturally were found to result in higher oxygen contents at the start of deoxidation. Furthermore, calculations of oxygen activities in the steel melt were made and the results were compared to measurements with varying results. Overall, the results indicate that calculation of oxygen activities with multivalence slag species such as $\mathrm{Fe}$ and $\mathrm{Cr}$ requires additional measurements to obtain accurate results.
\end{abstract}

Keywords: ladle, deslagging, oxygen activity, cleanness, sulphur, stirring. 


\section{Introduction}

The steelmaking process is and has always been characterised as a process, which continuously needs to be improved. One reason is that the demands from the customers of an increased cleanness continuously becomes more stringent, in order to obtain improved material properties. Another reason is that steelmaking of high-alloyed steel grades represents a task that not always can be theoretically predicted. For example, it might be difficult to carry out thermodynamic calculations due to lack of experimental data for these systems in order to verify the theoretical predictions. Thus, in general it is important for steel makers of high-alloyed steel grades in particular, to improve the processes based on plant experiments as well as based on new theoretical knowledge, in order to stay competitive in the global market.

Since the start of steelmaking a continuous development of the best process practice has been ongoing. Major milestones have been the introduction of the basic oxygen furnace (BOF), Bessemer process, open hearth furnace, electric arc furnace (EAF), uphill casting, continuous casting and vacuum treatment. Later, the development focused on improving the already existing process route such as improving the ladle refining process which is the focus of this paper.

In this paper the focus is oxygen activity and aluminium content based on plant trials. Here, it should be stated that the work by Wijk focusing on inclusion engineering has served as an inspiration for or research group and many other researchers [1]. In 1995, he reported the importance to control the amount, size, size distribution and composition of non-metallic inclusions in order to reach optimum steel properties to obtain a steel performance within tight specifications. Since then our group has carried out many studies focusing on determining how the inclusion characteristics vary during ladle treatment, based on plant trials [2-6]. Plant trials have also been made to study the following aspects of ladle refining operations:

i) the effect of deoxidation praxis and ferroalloy additions on the inclusion characteristics [7-9],

ii) the influence of the slag on the inclusion characteristics and sulphur content [10-13],

iii) the influence of stirring on the inclusion characteristics [14-17] and the influence of sampling on determining the inclusion characteristics in process samples [18-21].

The current study has been made at Uddeholms $\mathrm{AB}$ and is mainly focusing on the production route and its properties. During the last decade many studies have been made at Uddeholms AB looking at the ladle treatment where the main focuses have been the inclusion characteristics and their formation [22-27] as well as the removal of hydrogen [28-29], and the main steel grade investigated in these studies is presented in this study as steel grade A. Hence, only one heat of this steel grade is presented since it has been shown that this steel grade is very consistent in the process. It is known that these two steel grades, namely grade A and B, have a similar process route and somewhat different chemical steel compositions, but large difference in the dissolved oxygen content. The 
specific focus in this study is to compare how the steel characteristics differ between two different steel grades, hence indicating how the dissolved oxygen content may follow.

\section{Theory}

Steel cleanliness can be defined in many ways. However, in general a steel grade is considered to be clean if it contains low levels of oxygen, sulphur, nitrogen and hydrogen. Moreover, if the total oxygen content is low the oxygen inclusion content also can be kept low [30]. This is highly desirable for most steel grades since inclusions generally have a negative effect on most mechanical properties. The lowering of the total oxygen in the steel is initiated by the addition of a strong deoxidiser. More specifically, by the addition of an element which has a high affinity to oxygen according to the Ellingham diagram. Thereafter, the element will react with dissolved oxygen under the formation of an oxide according to the following reaction:

$$
\mathrm{x} \underline{\mathrm{Me}}+\mathrm{y} \underline{\mathrm{O}}=\mathrm{Me}_{\mathrm{x}} \mathrm{O}_{\mathrm{y}}
$$

where $\mathrm{Me}$ is a strong oxidiser, $\mathrm{O}$ is the dissolved oxygen, and $\mathrm{MeO}$ is the oxide. In industry, the strong deoxidiser Me could be $\mathrm{Si}, \mathrm{Al}$, Ti and $\mathrm{C}$. However, in some cases, there are steel grades where an element can act both as an alloying element and a deoxidiser, such as in the case of Mn.

When considering the sulphur content, many studies have been made to investigate the best practice [31-33]. Normally desulphurisation is discussed in combination with oxygen content. However, in this study the influence of sulpur refining on the aluminium content will be in focus. The desulphurisation reaction may be described as follows:

$$
\begin{aligned}
& \underline{S}+\left(O^{2-}\right)_{\text {slag }}=\underline{O}+\left(S^{2-}\right)_{\text {sla }} \\
& 2 \underline{A l}+3 \underline{O}=\mathrm{Al}_{2} \mathrm{O}_{3}(s) \ldots \ldots \ldots \ldots . .
\end{aligned}
$$

Hence, the dissolved sulphur is removed to the slag and the dissolved aluminium has formed alumina inclusions. However, it is not only the desulphurisation which causes the aluminium to be lowered during refining. According to Andersson et al. [34] it is stated that during vacuum treatment $\mathrm{FeO}, \mathrm{MnO}$ and $\mathrm{SiO}_{2}$ are being reduced by aluminium. Thus, the dissolved aluminium reacts with these oxides, which leads to a decrease of the dissolved aluminium content in the steel. This can be exemplified with the following reaction:

$$
3 \mathrm{FeO}+2 \underline{\mathrm{Al}}=\mathrm{Al}_{2} \mathrm{O}_{3}+3 \mathrm{Fe}
$$




\section{Process description}

At Uddeholms $A B$, the steel making process is scrap based. In the first part of the process, an electric arc furnace (EAF) of a 70 tonnes capacity is used to produce nearly finished steel with respect to the chemical composition of steel. After tapping into a ladle, the steel is deslagged. Then, a new synthetic slag is added together with deoxidisers and the remaining alloying adjustments. When the steel has the right temperature and chemical steel composition, the ladle is transferred to the vacuum degassing station where the steel undergoes its last treatment. During the whole process the steel is stirred by induction stirring. Furthermore, in the vacuum degassing station argon is used in combination with induction to create a strong stirring.

The prescribed process routes for the two steel grades in this study are almost the same. More specifically, in the EAF the starting material is recycled scrap of the specific steel grade. Thereafter, the treatment in the following steps uses the same route, namely refining in a ladle furnace (LF) followed by a vacuum degassing (VD) treatment. More specifically, the same amount of deoxidisers, synthetic slag and vacuum degassing time are used. The major difference, apart from the chemical steel composition is the casting temperature, which differs by 30 degrees.

\section{Experimental work}

Steel and slag samples were collected and the dissolved oxygen content in the steel was measured in the ladle. Specifically, a Celox lance was used to measure the dissolved oxygen. The samples were taken at five different process steps during the refinement of steel in the ladle, as shown in Figure 1. The labelling of the samples corresponds to the following definitions:

i) BD: a sample taken a short time after the steel has been tapped into the ladle, before a deslagging of the electric arc furnace slag,

ii) $\mathrm{AD}$ : a sample taken after a deslagging of the electric arc furnace slag,

iii) DH02: a sample taken after the first (and maybe the only) addition of alloying elements,

iv) BV: a sample taken before vacuum treatment, and

v) AV: a sample taken after vacuum treatment.

\section{Thermodynamic calculations}

Thermodynamic calculations were made by using Thermo-Calc (TC) [35]. The calculations of the equilibrium oxygen activity considering the steel melt/top slag equilibrium were done by using two sets of different databases, namely the TCFE8+SLAG2 and TCOX5 databases [36-39]. Only the major alloying elements were considered during the calculations. Also, the determined chemical steel composition was used together with the total oxygen content as input to the calculations. However, the Fe content was calculated as $100 \%$ minus the sum of the alloying elements. Also, the slag 
was first assumed to consist of stoichiometric oxides corresponding to the determined chemical slag composition. However, a comparison was made using the measured oxygen activity in the steel to set that as a condition for oxygen and make a calculation of the equilibrium between steel and slag. This was done to estimate the validity of the first assumption.

\section{Results and discussion}

Tables 1-4 show the chemical compositions of steel and slag. The values are presented and discussed in the following text. The two steel grades are denoted as A and BX, where $\mathrm{X}$ is the heat number of steel grade B. In some figures, not all heats are shown. This is due to that some values were judged to be extreme or due to that they were missing.

\section{Carbon content}

Figure 2 presents the carbon content in the steel during the different process steps. As can be seen, the content in two steel grades differs greatly. Thus, this may also cause the steel grades to behave differently during the different process steps during ladle refining. The A-steel has almost four times as high carbon content as the B-steel. When producing the steel grades used in this study only internally recycled scrap is used in the EAF. Hence, it is of interest to keep the existing valuable alloying elements in the steel melt without oxidising them. Thus, practically this removes the possibility to reduce the carbon content in the melt by an oxygen blowing procedure. As a direct result of this, the alloy additions used in the following process step, the ladle furnace, need to have low carbon contents. This can be seen in Figure 1, where the change in carbon content for steel grade A is due to that the carbon content increases due to that carbon is being added through alloy additions containing carbon. But for the B-steel, no or little change of the carbon content can be seen.

Carbon has a high oxygen affinity and is therefore a fairly strong deoxidiser at these temperatures. As a consequence, a low-carbon steel grade does not have as low dissolved oxygen content, when it is tapped into the ladle, compared to a high carbon steel grade. According to reaction 1, not enough carbon is available to deoxidise all oxygen present in the steel for a low-carbon steel grade. This may cause problems with the aluminium content later on in the process. If too much oxygen is left in the steel after desulphurisation (reaction 2), it will react with aluminium, as seen in reaction 3. Hence, for the B-steel which has a low carbon content it is plausible to find problems to maintain a stable as well as a predictable aluminium content throughout the remaining ladle refining process.

\section{Silicon content}

The silicon content in the studied heats and at different process steps is shown in Figure 3. Similar to carbon, silicon also has a high oxygen affinity. Thus, silicon is also a strong deoxidiser. As can be seen in Figure 3, the A-steel has an almost five times higher silicon content than the B-steel. Thus, the same way of reasoning may be applied for silicon as for carbon concerning the oxygen content in the steel. Hence, as the silicon content is 
increased the total oxygen content is decreased (shown as the total oxygen index). This can be seen in Tables 1 and 2. More specifically, the oxygen activity index is much higher for steel grade B than for steel grade A. In addition, if the content of silicon in the steel is too low it may result in high total oxygen contents if no other deoxidisers are present. The dissolved oxygen can later on react with aluminium under the formation of alumina inclusions (reaction 3).

\section{Aluminium content}

Figure 4 shows the variation of the aluminium content in the different process steps. The results may be interpreted as if there have been different additions of aluminium to the heats after the $\mathrm{AD}$ sampling. However, as seen in Table 5, the additions are fairly similar, namely 60 to $75 \mathrm{~kg}$ (95 kg is an extreme case). Also, when looking at the other alloys being added, which represent an addition of oxygen to the melt, the quota of $\mathrm{kg}$ aluminium versus the mass of alloys is within the same range for almost all of the heats. More specifically, the quotas are ranging from 2.0 to $2.6 \mathrm{wt}-\%$, with one exception where the value is $0.9 \mathrm{wt}-\%$. Hence, something else than the alloy addition cause the aluminium contents to vary between the different heats. Malmberg [27] has reported that increased amounts of slag during ladle refining leads to increased oxygen activities. This, in turn, leads to decreased dissolved aluminium contents in the steel. This is due to that aluminium is consumed when it reacts with dissolved oxygen to keep the dissolved oxygen value at an equilibrium content, which is determined by reaction 3 . However, according to Figure 4 the effect of the slag amount on the aluminium content may only apply during the ladle treatment. This is due to that during the vacuum treatment process step (AV) it is seen that the aluminium content has reached almost the same level for all studied heats. This is due to that the oxygen content is very low in the atmosphere above the steel bath, which minimises the chances for reoxidation of the steel bath. Moreover, the stirring is very intense during vacuum degassing. This promotes a homogenisation of the composition in the steel bath, a separation of inclusions, and an intense mixing between the slag and the steel. Previous research has shown that a thermodynamic equilibrium between slag and steel with respect to sulphur may be obtained [40]. In addition, it has been seen that the composition of inclusions in the steel comes closer to the composition of the top slag. This could indicate that some sort of equilibrium between the top slag and the steel is being approached $[13,25]$ and/or that the top slag has been dispersed into the slag during the intense stirring. Thus, it is not strange that similar aluminium contents are reached in the different heats after a completed vacuum treatment, since these contents most likely are controlled by a steel/slag equilibrium that has been reached [41].

A recent investigation [40] has shown that less aluminium is maintained in the steel when a poor deslagging has been made. This can be seen when comparing the two steel grades in this study. In the case of steel grade B, a thin layer of slag remains after the completed deslagging operation. This will lead to a loss of aluminium in the steel, due to a reaction between the deoxidizer and the slag.

Oxygen activity, total oxygen index

The oxygen activity $\left(a_{O}\right)$ at different process steps is presented in Figure 5. What is noticeable in this figure is that heat $\mathrm{B} 2$ has a very high oxygen activity $\left(a_{O}\right)$ compared to 
the other heats, in the beginning of the ladle refining process. This may be due to the high amount of scrap that was added late in the electric arc furnace process for heat B2. In Figure 6, the total oxygen index $\left(O_{t o t}\right)$ (total oxygen content at a specific time)/(maximum measured total oxygen content in this study) shows a scattered pattern in the beginning of the ladle treatment process. However, throughout the process the total oxygen index is lowered to a similar level for all studied heats. Specifically, the A-heat obtains an oxygen index $\left(O_{t o t}\right)$ of 0.05 and the B-heats obtain values between 0.02 and 0.08 . This is an evidence of that the deoxidation operations has been successful in all cases.

\section{Sulphur content}

Figure 7 shows the sulphur content in the steel and slag throughout the ladle treatment for the A-heat and two B-heats. The two B-heats were chosen due to that their aluminium contents before vacuum degassing were high and due to that data were available for all process steps. In this figure it can be seen that the final sulphur content is the lowest for steel grade A $(0.0003 \mathrm{wt}-\%)$, which may be explained by the higher aluminium content. More specifically, it is possible to reach low dissolved sulphur contents if the oxygen activity is low (reaction 2). This, in turn, is determined by the equilibrium with aluminium (reaction 3), which is the strongest deoxidiser present in the steel grade. This can also be seen from the different sulphur contents in the slag, where the highest value can be found in the A-heat. Most of the sulphur removal is made during the vacuum treatment, by a vivid reaction between slag and steel caused by the strong stirring. Since the two studied steel grades have the same vacuum treatment time, the degassing time should not be the cause for the different sulphur removal results. However, as mentioned earlier, thermodynamic conditions cause differences in sulphur levels. Specifically, high aluminium contents lead to low oxygen activities. This, in turn, leads to low sulphur levels as seen in figure 8. For the A-heat the oxygen activity level is low, the sulphur level is low, and the aluminium content is high. For the B-heats, the sulphur contents are higher and the aluminium contents are lower than for the A-heat. This may be the cause for the higher measured oxygen activity for the B-heats in comparison to the A-heats.

\section{$\mathrm{FeO}+\mathrm{MnO}$ content}

In figure 9, the sum of the $\mathrm{FeO}$ and $\mathrm{MnO}$ contents in the slag is plotted versus the aluminium contents, for values representing the process step DH02. It is seen that the $\mathrm{FeO}+\mathrm{MnO}$ content is very high, $>20 \mathrm{wt}-\%$, and that the aluminium content is very low, $<0.010 \mathrm{wt}-\%$ for heat B2. This may be caused by two different things. Firstly, there was an extra addition of scrap very late in the electric arc furnace process. This rendered a larger amount of slag in the electric arc furnace as well as an extra addition of oxygen to the steel. Secondly, the deslagging process at the ladle station may have been poorly done. In the figure it can be seen that a lower $\mathrm{FeO}+\mathrm{MnO}$ content in the slag results in a higher aluminium content in the steel. This is due to that the following reoxidation reactions can be minimised:

$$
\begin{aligned}
& 3 \mathrm{FeO}+2 \underline{\mathrm{Al}}=\mathrm{Al}_{2} \mathrm{O}_{3}+3 \mathrm{Fe} . \\
& 3 \mathrm{MnO}+\underline{2 \mathrm{Al}}=\mathrm{Al}_{2} \mathrm{O}_{3}+3 \mathrm{Mn}
\end{aligned}
$$


Figure 10 shows the $\mathrm{FeO}+\mathrm{MnO}$ content in slag versus the sulphur content in the steel. Steel grade A (marked in the figure) has the lowest $\mathrm{FeO}+\mathrm{MnO}$ values for respective process step. At process step BD, the electric arc furnace slag is still in the ladle. Due to the high manganese content in the $\mathrm{B}$-steel, the slag has been enriched in $\mathrm{MnO}$ during the electric arc furnace treatment, see Table 4. If the values of process step BD are neglected in Figure 11, it can be seen that a lower $\mathrm{FeO}+\mathrm{MnO}$ content in the slag corresponds to a lower sulphur content in the steel. Furthermore, that the A-steel has a lower $\mathrm{FeO}+\mathrm{MnO}$ content and a lower sulphur content than the B-steel during all process steps.

\section{CaO content}

The $\mathrm{CaO}$ in slag versus the aluminium content in the steel is presented in Figure 12. In this figure, the A-heat has been marked to clearly separate the results from the different B-heats. At process step BD, all steel samples have very low aluminium contents. This is due to that no aluminium deoxidation has been done at this process step and due to that the $\mathrm{CaO}$ content is still low, namely less than $40 \mathrm{wt}-\%$ (electric arc furnace slag). It is also seen that the aluminium content decreases with the process time for all heats. In addition to this, the A-heat has the highest aluminium content in the steel as well as the highest $\mathrm{CaO}$ content in the slag for all process steps. However, since the slag addition is the same for all heats the composition should not differ. One reason for the difference may be a poor deslagging operation. According to the operators, the EAF slag is typically not completely removed during the deslagging for steel grade $\mathrm{B}$. This is due to that the slag properties make it difficult to perform a successful deslagging operation for this steel grade, the EAF slag of steel grade B behaves slippery at the end of the deslagging process and therefore the rake is not able to catch the pools of slag left in the ladle. Since the EAF slag of steel grade $\mathrm{B}$ has a high $\mathrm{FeO}+\mathrm{MnO}$ content as well as a high $\mathrm{Cr}_{2} \mathrm{O}_{3}$ content, the new added slag will not have the same $\mathrm{CaO}$-content as the slag used for steel grade $\mathrm{A}$.

\section{$\mathrm{MgO}$ content}

In figure 13, the $\mathrm{MgO}$-content in slag for different process steps is shown. No significant difference between the heats or the steel grades is seen. The only thing that can be seen is that the $\mathrm{MgO}$-content for heat $\mathrm{B} 5$ increases greatly during the process. The difference between heat B5 and the other heats is that it has a somewhat higher Si-content in the steel. Since manganese may be aggressive to refractories, studies $[42,43]$ have been made to investigate the possibility of high MnO-slags to react with the refractory. It has not been verified that $\mathrm{MnO}$ may cause an exceeding erosion of the refractory. However, another aspect not taken into account may be the age of the ladle. Specifically, it is necessary to consider if the ladle wear is high or if the ladle is new. In the case of heat B5 the ladle is fairly new, namely the ladle has only been used for 3 heats. One way of detecting refractory loss is to monitor the $\mathrm{MgO}$ content in the slag [44]. Usually it is necessary, from the beginning of the process, to have approximately $12-14 \mathrm{wt}-\% \mathrm{MgO}$ in the slag to keep it from being too aggressive. More specifically, if the $\mathrm{MgO}$ content is too low there will be a large driving force for a reaction between the basic slag and the $\mathrm{MgO}$ based refractory lining. 


\section{SiO2 content}

The $\mathrm{SiO}_{2}$ content in slag is shown in Figure 14. As can be seen, the $\mathrm{SiO}_{2}$ content is at its highest in sample BD for all heats. This is due to that the EAF-slag contains lots of $\mathrm{SiO}_{2}$, since silicon is used to reduce the EAF slag during tapping. When the new synthetic slag is added, the $\mathrm{SiO}_{2}$ content remains constant throughout the rest of the process (10 wt-\%) for heat $\mathrm{A}$. When looking at the $\mathrm{SiO}_{2}$ content for the B-heats, it can be seen that the content varies during the ladle process. The $\mathrm{SiO}_{2}$ content in the new synthetic slag for the B-heats is also higher (12-18 wt-\%) than for the A-heat. This should not be the case, since the same addition of new slag is made. One reason that causes a different $\mathrm{SiO}_{2}$ content could be a difference in how successful the deslagging operation was performed. This carry-over slag is high in $\mathrm{SiO}_{2}$, which will influence the top slag composition after that a synthetic slag has been added in the ladle). Therefore, an attempt to make the same analysis as reported by Doostmohammadi et al. [26] was carried out. The results indicated that the slag carry-over was approximately five times larger for the B1 grade in comparison to the A grade. However, for the remaining B-heats the slag carry-over became negative, which indicates that the slag amounts can vary greatly during production. This can also be seen from the varying $\mathrm{CaO}$ concentrations, despite that similar $\mathrm{CaO}$ additions are being made during the ladle treatment.

\section{Oxygen activity calculations}

The calculations of the oxygen activity for steel grade A is seen in Figure 15. For the sample BD, the difference between the two calculations (two different databases) and the measured value is not so large. Specifically, the calculated value is approximately 60 to $90 \%$ of the measured activity. This is also visible in Figure 16 (however for an opposite relation, where the calculated value is higher than the measured value), where the calculated oxygen activities for steel grade B are shown. However, when looking at the sample BV the difference between the two calculated values and the measured values is far greater. Specifically, the calculated value is $15 \%$ of the measured value for steel grade A and some calculated values as low as $30 \%$ of the measured values for steel grade B. The same is seen for sample AV, where the calculated value for steel grades A and B are approximately $30 \%$ and $20-40 \%$ of the measured value, respectively. The discrepancy between the calculations and the measured values could be due to that the steel comes in contact with the surrounding air during the deslagging operation (between BD and BV, see Figure 1). Hence, it is possible that the dissolved oxygen content is increased due to a reoxidation caused by reactions with oxygen in the air. This has not been taken into account when calculating the oxygen activities for the latter process steps. Another parameter that may affect the outcome of the calculations is the variation of the dissolved oxygen content in the steel. As seen in Table 6, the oxygen activity before deoxidation (BD) varies between 108 to $273 \mathrm{ppm}$ for steel grade B. Thereafter, the values have less variation, namely 6 to $23 \mathrm{ppm}$. It is also noticed in Figure 15 that the measured oxygen activity for process step BD is lower than that of the calculated value. However, in all other cases the situation is the reverse.

The relative deviations can readily be represented by the results presented in Figure 17, by comparing the calculated oxygen activities to the Celox measurements. Note, that the relative error is small for sample BD compared to the BV and AV samples. According to the data of Celox probes [45], the standard probe Celox Al should not be used for 
temperatures below $1570^{\circ} \mathrm{C}$. In the case of samples taken at $\mathrm{BD}$, the temperatures are in the lower range of the given temperature interval for this probe. Furthermore, at sample AV the temperatures were in the range of $1550-1600^{\circ} \mathrm{C}$. Thus, most of the measurements were lower than the given range of the temperature interval for the Celox probe. If the measured uncertainties are assumed to be small and the measured values are taken to be close to the actual oxygen activity, these values can be set as a condition for the oxygen activity. Figure 18 illustrates a comparison between the original calculations to these "measured" calculations for an activity of $\mathrm{FeO}$ in the liquid slag. Similar to the results in Figure 17, the relative error of sample BD is smaller than for the BV and AV samples. One interpretation of this result is that the available oxygen in the system is poorly estimated due to the use of the assumption that multivalent species, such as $\mathrm{Fe}$ and $\mathrm{Cr}$, only are present in a single valence state, e.g. $\mathrm{Fe}^{2+}$ and not as a mixture of $\mathrm{Fe}^{2+}$ and $\mathrm{Fe}^{3+}$. Therefore, the $\mathrm{Fe}^{2+} / \mathrm{Fe}^{3+}$ ratio should ideally be measured to make a more certain conclusion. Furthermore, future studies should also be made to determine to what extent the Celox measurements can be used to predict the liquid slag state.

\section{Conclusions}

The present paper discusses the process control during ladle refining in order to produce a clean steel grade. A special attention is given to the variations of the oxygen and aluminium contents in the steel. The study has been done based on plant trials for two different steel grades, but with similar process treatments. Overall, it was found that the deslagging and deoxidation processes are of great importance to control in order to make a clean steel. If the deslagging operation is not carried out in an appropriate manner, the steel will have a lower Al-content and hence a higher O-content.

The most specific conclusions from this study may be summarised as follows:

- Low contents of deoxidisers such as C and Si makes it difficult to keep a low dissolved oxygen content in the steel, which is reflected in a low aluminium content during the beginning of ladle treatment.

- The oxygen activity and total oxygen varies throughout the process, but stabilises to similar levels at the end of ladle treatment for all heats

- The study confirms the well-known fact that the dissolved oxygen content in the latter part of the process controls the possibility to reach a successful desulphurisation. Comparing two different steel grades with similar process routes with regard to desulphurisation shows, that the aluminium loss corresponds to an increased dissolved oxygen content caused by the desulphurisation reactions.

- A lower $\mathrm{FeO}+\mathrm{MnO}$ content in the slag indicate that less reoxidation has taken place, which increases the possibilities to control the aluminium content. Thus, a careful deslagging operation is important to reach a stable aluminium content and a small reoxidation.

- Calculations of oxygen activity show that the results do not differ much depending on which set of database was used. However, when compared with measured values, the predicted values are 60 to $150 \%$ and 15 and $100 \%$ of the measured values for the BD-samples and for the BV- and AV-samples, 
respectively. This is most likely due to the assumption that all oxygen can be summed up as assumed stoichiometric oxides and as a consequence the true oxidation state is not taken into account.

It is the authors' strong belief that it is necessary to implement techniques to control and limit the amount of slag that is transferred from the EAF to the ladle in order to improve the cleanliness of the steel in the future. For example, it could be very helpful to use an IR-camera to determine the remaining slag amount after a completed deslagging operation. Thus, the remaining ladle refining process could be adjusted based on this amount of furnace slag as well as the use of oxygen activity measurements, in order to reach the desired clean steel demands.

\section{Acknowledgements}

The authors wish to thank Uddeholms AB for financial support to this study. We would also wish to thank the operators in the steel melting shop for their help with sampling and fruitful discussions during experiments. A special thanks to Mikael Svensson at Uddeholms AB for his support in finding relevant historical data for this study. 


\section{References}

1. O. Wijk: Proc. Scaninject VII, MEFOS, Luleå, Sweden, June 1995, 35.

2. P. Sjödin, P.G. Jönsson, M. Andreasson, and A. Winqvist, "Oxidic steel cleanness in high-carbon chromium bearing steel", Scand. J. Met., Vol. 26, No. 1,1997, p.41.

3. E. Fuchs and P. Jönsson, "Inclusion characteristics in bearing steel before and after ingot casting", High Temp. Mat. and Proc.Vol. 19, No. 5 (2000), pp. 333344.

4. J. Cheng, R. Eriksson and P. Jönsson, "Determination of Macro Inclusions during Clean Steel Production”, Ironmaking and Steelmakin, 30, 2003, pp. 66-72.

5. R. Eriksson, P. Jönsson and A. Gustafsson, "Determination of Inclusion Characteristics in Low-Carbon Steel during Up-Hill Teeming”, Scandinavioan J. Metallurgy, 33, 2004, pp. 160-171.

6. K.M. Steneholm, A.M.T. Andersson, P.G. Jönsson, "Change of Inclusion Characteristics during Vacuum Degassing of Tool Steel”, Steel Research International, No.6, 2006, 392-399.

7. L. Huet, P. Jönsson and F. Reinholdsson, "The effect of deoxidation practise on inclusion characteristics in bearing steel production", Steel Times Int., Nov. 1997, p. 47-50.

8. J. Björklund, M. Andersson, M. Nzotta and P. Jönsson, "The Effect of Ladle Treatment on Inclusion Composition in Tool Steel Production", Steel Research International, Vol. 79, No. 4, 2008, pp. 261-270.

9. T. Sjöqvist, M. Göransson, P. Jönsson and P. Cowx, "Influence of Ferromanganese on Micro-Alloyed Engineering Steel", Ironmaking and Steelmaking, 30, 2003, pp. 73-80.

10. T. Sjöqvist, S. Jung, P. Jönsson and M. Andreasson, "Influence of Calcium Carbide Slag Additions on Inclusion Characteristics in Steel”, Ironmaking and Steelmaking, Vol. 27, No. 5, 2000, pp. 373-380.

11. M. Andersson, M. Hallberg, L. Jonsson and P. Jönsson, "Slag-metal Reactions during Ladle Treatment with Focus on Desulphurisation", Ironmaking and Steelmaking, Vol. 29, No. 3, 2002, p. 224.

12. J. Björklund, M. Andersson and P. Jönsson, " Equilibrium between slag, steel and inclusions during ladle treatment: comparison with production data", Ironmaking and Steelmaking”, Vol. 34, No. 4 (2007), 312-324.

13. K. Steneholm, M. Andersson, M. Nzotta and P. Jönsson, "Effect of Top Slag Composition on Inclusion Characteristics during Vacuum Degassing of Tool Steel”, Steel Research International. No.7 (2007), 522-530.

14. Mats Söder, Pär Jönsson, Lage Jonsson, Mselly Nzotta, ”An Experimental Study of Number Concentration Gradients of Inclusions during Deoxidation using Inductive and Gas Stirring”, Steel Research International, No. 7, 2005, pp. 481490. 
15. K. Malmberg, M. Nzotta, A. Karasev and P.G. Jönsson, ”Optimisation of stirring condistions during vacuum degassing in order to lower the inclusion content in steel”, ”, Ironmaking and Steelmaking, Vol. 40, No. 3, 2013, pp. 231-237.

16. K. Malmberg; A. Karasev; M. Nzotta; J. Alexis; P. G. Jönsson, "Influence of final stirring treatment on inclusion number in tool steel", Ironmaking and Steelmaking, Vol. 40, No. 6, 2013, pp.407-412.

17. C. Medioni, P. Jönsson, D. Sichen, "Effect of stirring practice on sulphur and nitrogen refining as well as inclusion removal in ladle treatment", Steel Research International, 2014. http://dx.doi.org/10.1002/srin.201400501

18. T. Hansen, P.G. Jönsson, S.E. Lundberg and K. Törresvoll, 'The Concept of the Liquid Sampling and Hot Rolling Method for Determination of Macro Inclusion Characteristics in Steel, Steel Research International, No. 3, 2006, pp. 177-185.

19. O.T. Ericsson, A.V. Karasev and P.G. Jönsson, "Effect of Slag Protection System and Sample Geometry on Homogeneity of Total oxygen Content in Samples from Liquid Steel", Steel Research International, Vol. 82, No. 3, 2011, pp. 222-229.

20. O.T. Ericsson, A.V. Karasev and P.G. Jönsson: "Effect of Slag Protection System and Sample Geometry on Homogeneity of Total Oxygen Content in Samples from Liquid Steel", Steel Res. Int., 82, 2011, No.3, 222-229.

21. O.T. Ericsson, M. Lionet, A.V. Karasev, R. Inoue and P.G. Jönsson, "Changes in inclusion characteristics during sampling of liquid steel", Ironmaking and Steelmaking, Vol. 39, No. 1, 2012, pp. 67-75.

22. K Beskow: Formation and Chemical Development of Non-metallic Inclusions in Ladle Treatment of Steel, Doctoral Thesis, Stockholm, Sweden, 2003

23. N N Tripathi: A Study on the Population and Chemical Development of NonMetallic Inclusions in the Tool-Steel Making Process, Doctoral Thesis, Stockholm, Sweden, 2004

24. Y J Kang: Some aspects of non-metallic inclusions during vacuum degassing in ladle treatment : with emphasize on liquid CaO-A12O3 inclusions, Doctoral Thesis, Stockholm, Sweden, 2007

25. J Björklund: Thermodynamic Aspects on Inclusion Composition and Oxygen Activity during Ladle Refining, Doctoral Thesis, Stockholm, Sweden, 2008

26. H. Doostmohammadi: A Study of Slag/Metal Equilibrium and Inclusion Characteristics during Ladle Treatment and after Ingot Casting, Doctoral Thesis, Stockholm, Sweden, 2009

27. K Malmberg: Some aspects of inclusion control and behavior with focus on secondary metallurgy, Stockholm, Sweden, 2012

28. J Brandberg: Solubility of Hydrogen in Slags and its Impact on Ladle Refining, Licentiate Thesis, Stockholm, Sweden, 2006 
29. K. Steneholm, M. Andersson, A. Tilliander and P.G. Jönsson, "Removal of hydrogen, nitrogen and sulphur from tool steel during vacuum degassing", Ironmaking and Steelmaking, Vol. 40, No. 3, 2013, pp. 199-205.

30. J. Wikström, K Nakajima, P. Jönsson: Application of a Model for Liquid Inclusion Separation at a Steel- Slag Interface for Laboratory and Industrial Situations, steel research int. 79, 2008, No. 11, pp826-834

31. M.A.T. Andersson, P.G. Jönsson, M. Hallberg: Optimisation of ladle slag composition by application of sulphide capacity model, Ironmak. Steelmak., 2000, Vol. 27, No.4, pp286-293

32. Margareta A.T. Andersson, Pär G. Jönsson and Mselly M. Nzotta: Application of the Sulphide Capacity Concept on High-Basicity Ladle Slags Used in BearingSteel Production, ISIJ International, 1999, Vol. 39, No. 11, pp 1140-1149

33. P.G. Jönsson, L Jonsson and D. Sichen: Viscosities of LF Slags and their Impact on Ladle Refining, ISIJ International, 1991, Vol 37, No.5, pp 484-491

34. A.M.T. Andersson, L.T.I Jonsson, P.G. Jönsson: A model of reoxidation from the top slag and the effect on sulphur refining during vacuum degassing, Scand. Journal of Met. 2003: 32, pp.123-136

35. J.O. Andersson, T. Helander, L. Höglund, P.F. Shi, and B. Sundman: ThermoCalc and DICTRA, Computational tools for materials science. Calphad, 2002, 26, pp. 273-312.

36. Thermo-Calc Software TCFE8 Steels/Fe-alloys database version 8, (Accessed 4 Apr 2016)

37. Thermo-Calc Software TCOX5 Metal Oxide Solutions Database version 5, (Accessed 4 Apr 2016)

38. Thermo-Calc Software SLAG2 Fe-containing Slag Database version 2.2, (Accessed 4 Apr 2016)

39. H. Gaye and Welfringer: in 2nd Int. Symp. Metall. Slags Fluxes, Warrendale, PA., Metall. Soc. AIME, 1984, p. 357

40. Private communication with Ph.D. M.M. Nzotta, Uddeholms AB, Hagfors, Sweden, March-April 2014

41. Z. Deng, M. Zhu: Deoxidation Mechanism of Al-Killed Steel during Industrial Refining Process, ISIJ, 2014, pp 1498-1506

42. A. Ikesue, H. Yamamoto, H. Shikano, K. Hiragushi: Corrosion Mechanism of MgO-C Refractories by Manganese Oxide containing Slag, Advances in Refractories Technology. Proc. Int. Forum on Advances in Refractories Technology Cincinnati, 2-4 May 1988, pp. 464-488

43. M.-A. Van Ende, M. Guo, P. T. Jones, B. Blanpain, P. Wollants: Degradation of $\mathrm{MgO}-\mathrm{C}$ Refractories by MnO-rich Stainless Steel Slags, Ceramics International, 2009, 35, pp. 2203-2212 
44. J. Pierard, D Sichen, P Jönsson, S Seetharaman, T Landin: Effect of slag on carbon bearing $\mathrm{MgO}$ refractories, Ironmaking \& steelmaking, 1998, v.25, no.5, pp.374-381

45. www.heraeus-electro-nite.com; Celox_application_manual.pdf 
Table 1: Chemical composition of steel, steel grade A.

\begin{tabular}{l||llllll} 
Sample & $\mathrm{C}(\mathrm{wt}-\%)$ & $\mathrm{Si}(\mathrm{wt}-\%)$ & $\mathrm{S}(\mathrm{wt}-\%)$ & $\mathrm{Al}(\mathrm{wt}-\%)$ & $\begin{array}{l}\mathrm{a}_{\mathrm{O}} \text {-index } \\
\left(a_{O}\right)\end{array}$ & $\begin{array}{l}\text { O-index } \\
\left(O_{\text {tot }}\right)\end{array}$ \\
\hline \hline A-BD & 0.31 & 0.34 & 0.008 & 0.001 & 0.051 & 0.10 \\
A-AD & 0.31 & 0.33 & 0.007 & 0.002 & -- & 0.15 \\
A-DH02 & 0.38 & 0.98 & 0.0037 & 0.08 & 0.004 & 0.03 \\
A-BV & 0.37 & 1.0 & 0.0026 & 0.06 & 0.010 & 0.04 \\
A-AV & 0.40 & 1.0 & 0.0003 & 0.018 & 0.004 & 0.05 \\
\hline
\end{tabular}

Table 2: Chemical composition of steel, steel grade B.

Sample $\quad \mathrm{C}(\mathrm{wt}-\%) \quad \mathrm{Si}(\mathrm{wt}-\%) \quad \mathrm{S}(\mathrm{wt}-\%) \quad \mathrm{Al}(\mathrm{wt}-\%) \quad a_{\mathrm{O}-i n d e x} \quad$ O-index

\begin{tabular}{l||llllll}
\hline B1-BD & 0.079 & 0.042 & 0.01 & 0.001 & -- & $\left(a_{O}\right)$ \\
B1-AD & 0.08 & 0.024 & 0.01 & 0.002 & -- & 0.40 \\
B1-DH02 & 0.085 & 0.24 & 0.008 & 0.05 & 0.011 & 0.16 \\
B1-BV & 0.083 & 0.24 & 0.006 & 0.043 & 0.022 & 0.04 \\
B1-AV & 0.087 & 0.25 & 0.0028 & 0.007 & 0.021 & 0.02 \\
\hline \hline B2-BD & 0.028 & 0.012 & 0.0052 & 0.002 & -- & 1.00 \\
B2-AD & 0.026 & 0.008 & 0.0052 & 0.001 & 1 & 0.19 \\
B2-DH02 & 0.064 & 0.11 & 0.005 & 0.009 & 0.071 & 0.27 \\
B2-BV & 0.066 & 0.25 & 0.0036 & 0.005 & 0.056 & 0.13 \\
B2-AV & 0.097 & 0.24 & 0.0019 & 0.007 & 0.031 & 0.02 \\
\hline B3-BD & 0.085 & 0.032 & 0.008 & 0.001 & 0.374 & 0.51 \\
B3-AD & 0.08 & 0.016 & 0.009 & 0.001 & 0.285 & 0.23 \\
B3-BV & 0.088 & 0.24 & 0.006 & 0.047 & 0.025 & 0.12 \\
B3-AV & 0.098 & 0.24 & 0.0042 & 0.009 & 0.023 & 0.05 \\
\hline \hline B4-BD & 0.079 & 0.039 & 0.0051 & 0.001 & -- & 0.85 \\
B4-AD & 0.076 & 0.002 & 0.0054 & 0.001 & 0.409 & 0.86 \\
B4-DH02 & 0.073 & 0.22 & 0.0053 & 0.027 & 0.014 & 0.10 \\
B4-BV & 0.077 & 0.23 & 0.0043 & 0.019 & -- & 0.32 \\
B4-AV & 0.09 & 0.23 & 0.003 & 0.008 & 0.039 & 0.08 \\
\hline \hline B5-BD & 0.099 & 0.13 & 0.0053 & 0.002 & 0.194 & 0.57 \\
B5-AD & 0.097 & 0.11 & 0.0055 & 0.001 & 0.131 & 0.45 \\
B5-DH02 & 0.093 & 0.23 & 0.0048 & 0.07 & 0.004 & 0.05 \\
B5-BV & 0.097 & 0.28 & 0.0032 & 0.036 & 0.029 & 0.07 \\
B5-AV & 0.1 & 0.28 & 0.002 & 0.014 & 0.020 & 0.03 \\
\hline \hline
\end{tabular}


Table 3: Chemical composition of slag, steel grade A (wt-\%)

\begin{tabular}{l|llllll} 
Sample & $\mathrm{CaO}$ & $\mathrm{MgO}$ & $\mathrm{Al} 2 \mathrm{O} 3$ & $\mathrm{SiO} 2$ & $\mathrm{FeO}$ & $\mathrm{S}$ \\
\hline \hline A-BD & 37.2 & 17.6 & 6.22 & 31.1 & 1.59 & 0.051 \\
A-DH02 & 52.5 & 10.4 & 25 & 10 & 0.92 & 0.17 \\
A-BV & 55.4 & 9.99 & 23.1 & 10.4 & 0.41 & 0.2 \\
A-AV & 52 & 9.78 & 26.3 & 10.1 & 0.31 & 0.37 \\
\hline \hline
\end{tabular}

Table 4: Chemical composition of slag, steel grade B. (wt-\%)

\begin{tabular}{l||llllllll} 
Sample & $\mathrm{CaO}$ & $\mathrm{MgO}$ & $\mathrm{A} 12 \mathrm{O} 3$ & $\mathrm{SiO} 2$ & $\mathrm{FeO}$ & $\mathrm{MnO}$ & $\mathrm{Cr} 2 \mathrm{O} 3$ & $\mathrm{~S}$ \\
\hline \hline B1-BD & 32.8 & 18.8 & 6.59 & 28.4 & 2.15 & 7 & 1.35 & 0.029 \\
B1-DH02 & 49 & 12.4 & 19.9 & 15.5 & 0.58 & 1.05 & 0.14 & 0.14 \\
$\mathrm{~B} 1-\mathrm{BV}$ & 47.1 & 12.9 & 20.2 & 16.4 & 0.63 & 1.13 & 0.12 & 0.15 \\
$\mathrm{~B} 1-A V$ & 45.4 & 13 & 23.6 & 15.1 & 0.4 & 0.55 & 0.04 & 0.33 \\
\hline \hline B2-BD & 20.5 & 14.3 & 2.57 & 13.8 & 24.4 & 8.08 & 18.4 & 0.012 \\
$\mathrm{~B} 2-\mathrm{DH} 02$ & 33.4 & 11.5 & 15.8 & 12.4 & 5.83 & 14.7 & 4.09 & 0.031 \\
B2-BV & 50.4 & 10.8 & 22.8 & 14 & 0.57 & 0.9 & 0.13 & 0.052 \\
B2-AV & 46.8 & 11.5 & 23.4 & 15.5 & 0.48 & 0.55 & 0.06 & 0.16 \\
\hline B3-BD & 29 & 17.9 & 3.01 & 21.2 & 8.64 & 9 & 8.73 & 0.014 \\
B3-BV & 41.2 & 13.5 & 22.8 & 16.5 & 0.86 & 3.37 & 0.41 & 0.067 \\
B3-AV & 40.6 & 14.7 & 26.1 & 16.4 & 0.34 & 0.92 & 0.06 & 0.17 \\
\hline \hline B4-BD & 30.4 & 20.8 & 2.47 & 23.1 & 5.4 & 7.78 & 6.26 & 0.012 \\
B4-DH02 & 44.3 & 11.2 & 21 & 15.5 & 1.76 & 3.62 & 0.6 & 0.051 \\
B4-BV & 41.5 & 13.7 & 21.1 & 18.2 & 0.71 & 1.91 & 0.25 & 0.064 \\
B4-AV & 41.3 & 14 & 22.6 & 18.5 & 0.34 & 0.86 & 0.09 & 0.12 \\
\hline \hline B5-BD & 35.9 & 15.2 & 3.14 & 27.9 & 3.69 & 7.54 & 2.69 & 0.016 \\
B5-DH02 & 50.3 & 10.7 & 23.6 & 11.1 & 0.78 & 1.24 & 0.19 & 0.054 \\
B5-BV & 41.4 & 20.6 & 23.2 & 12.5 & 0.5 & 0.49 & 0.11 & 0.12 \\
B5-AV & 36.2 & 27.7 & 22.3 & 10.8 & 0.59 & 0.55 & 0.1 & 0.15 \\
\hline \hline
\end{tabular}

Table 5: Amounts of $\mathrm{Al}$ added as deoxidizer

\begin{tabular}{c|cc} 
Heat & Al-addition $(\mathrm{kg})$ & Quota of alloy added (\%) \\
\hline \hline A & 70 & 2.6 \\
B1 & 60 & 2.2 \\
B2 & 80 & 0.9 \\
B3 & 95 & 2.4 \\
B4 & 70 & 2.0 \\
B5 & 75 & 2.3 \\
\hline
\end{tabular}


Table 6: Oxygen activity calculations for two different databases and measured value Heat TCFE8+SLAG2 (ppm) TCOX5 (ppm) Measured (ppm)

\begin{tabular}{c|ccc}
\hline \hline A-BD & 20.788 & 15.043 & 22.5 \\
A-BV & 0.65973 & 0.7271 & 4.4 \\
A-AV & 0.46327 & 0.56019 & 1.7 \\
\hline \hline B1-BD & 89.756 & 74.811 & -- \\
B1-BV & 3.5105 & 3.6563 & 9.5 \\
B1AV & 1.6713 & 1.8472 & 9.4 \\
\hline \hline B2-BD & 593.74 & 871.49 & -- \\
B2-BV & 2.4152 & 2.6983 & 24.6 \\
B2-AV & 1.2569 & 3.6593 & 13.54 \\
\hline \hline B3-BD & 254.11 & 202.94 & 163.5 \\
B3-BV & 6.4079 & 5.9644 & 10.4 \\
B3-AV & 4.7298 & 4.8957 & 10.2 \\
\hline \hline B4-BD & 223.78 & 164.44 & -- \\
B4-BV & 7.6878 & 7.1824 & -- \\
B4-AV & 3.4065 & 3.6909 & 17.2 \\
\hline \hline B5-BD & 107.51 & 83.174 & 85.1 \\
B5-BV & 3.5057 & 3.7933 & 12.9 \\
B5-AV & 2.3272 & 2.5619 & 8.6 \\
\hline \hline
\end{tabular}




\section{Process timeline and sampling positions}

\section{1 - Deslagging}

2 - Aluminum addition

3 - Alloy addition

4 - Vacuum degassing

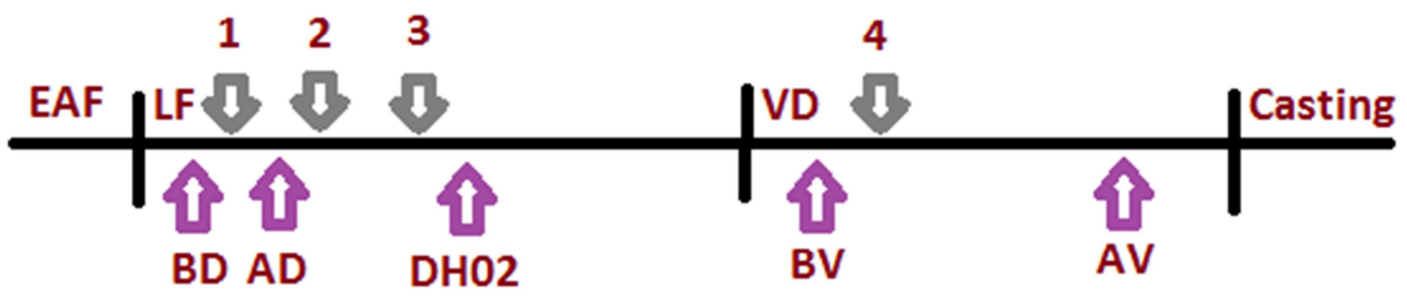

Figure 1. Process timeline and sampling positions in the process

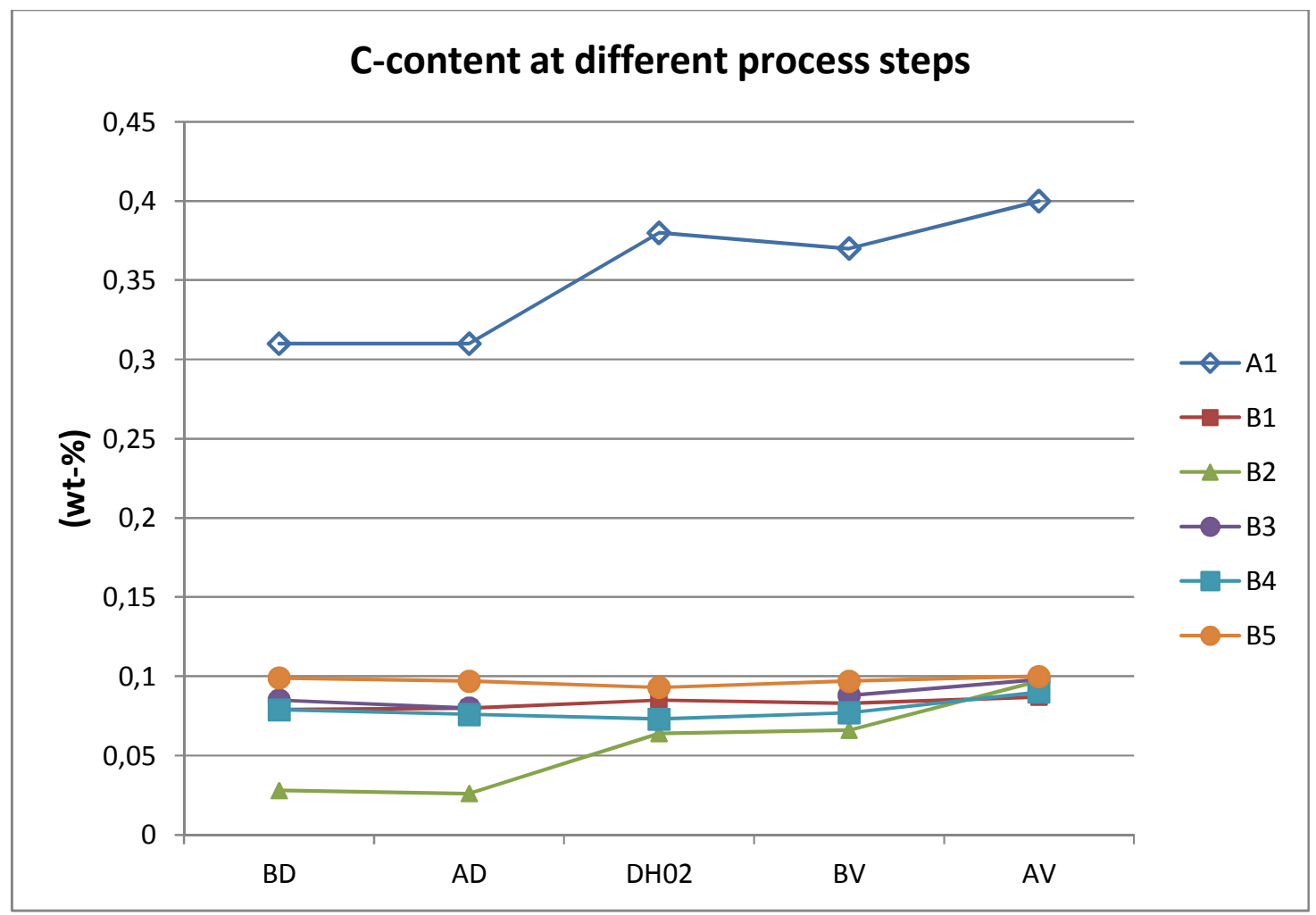

Figure 2. Carbon content in steel grades at the different process steps $\mathrm{BD}, \mathrm{AD}, \mathrm{DH} 02$, $\mathrm{BV}$ and AV. Data are given for both the A heat and the B heats (B1-B5). 


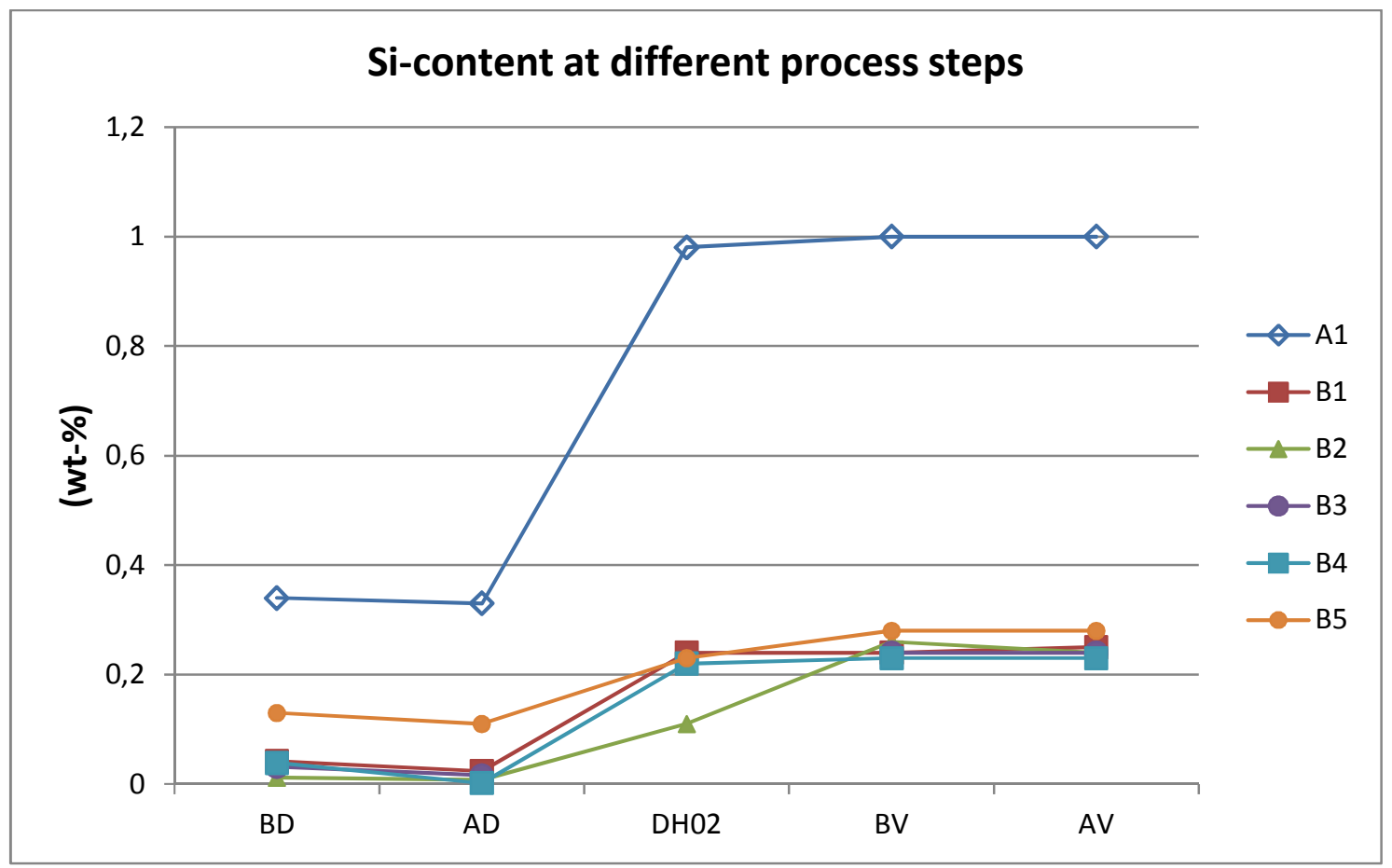

Figure 3. Silicon content in steel grades at the different process steps BD, AD, DH02, BV and AV. Data are given for both the A heat and the B heats (B1-B5).

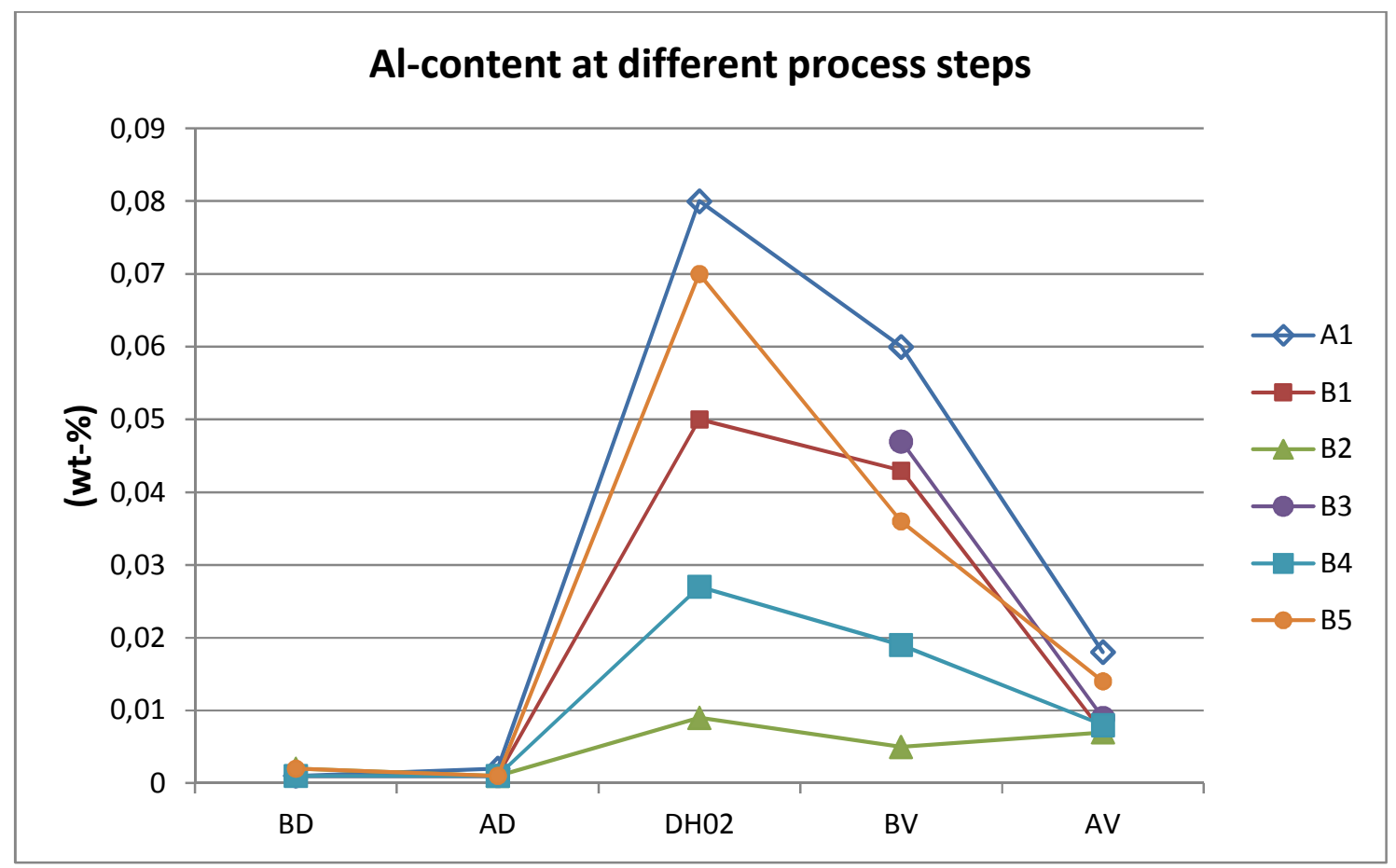

Figure 4. Aluminium content in steel grades at the different process steps BD, AD, DH02, BV and AV. Data are given for both the A heat and the B heats (B1-B5). 


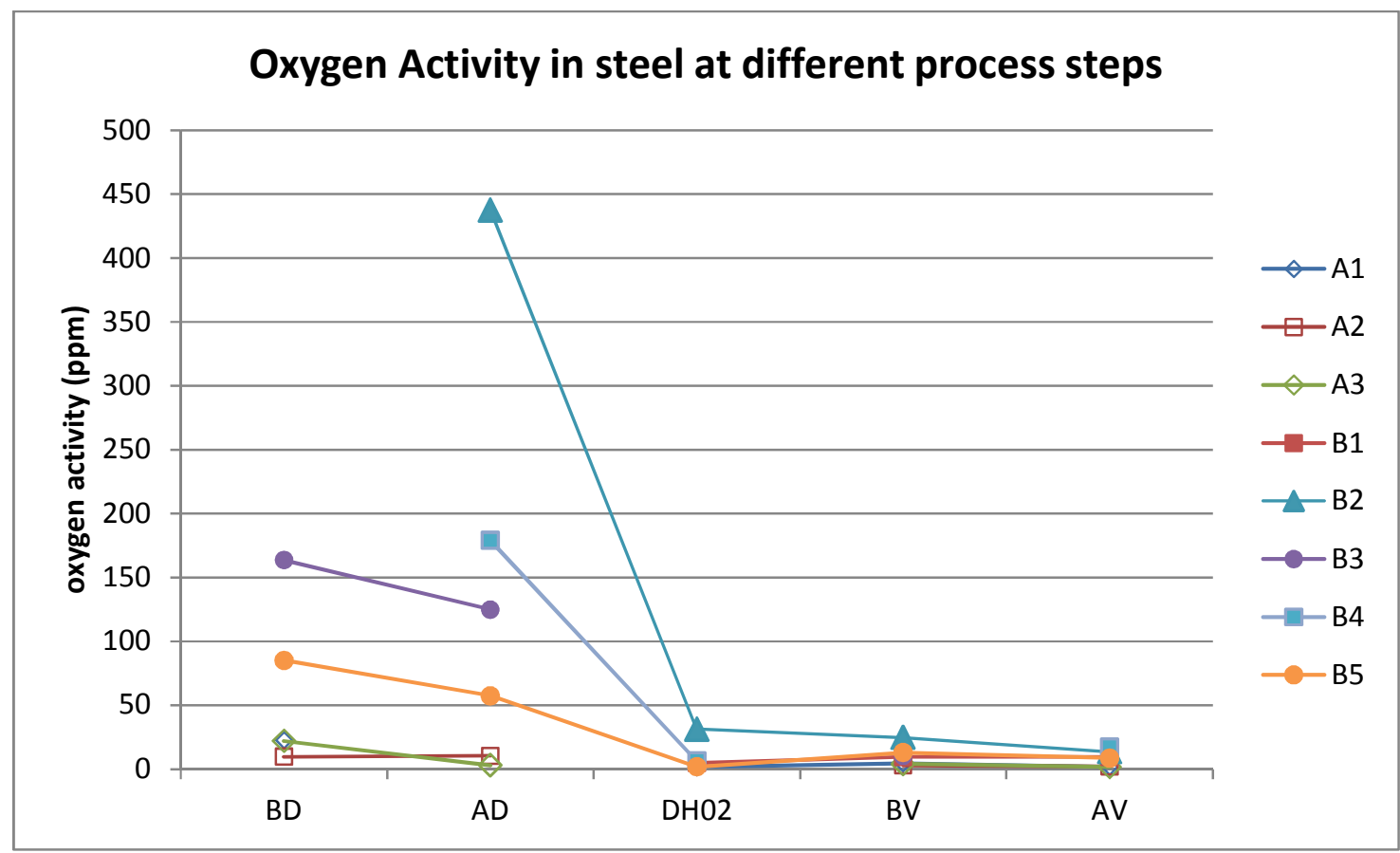

Figure 5. Oxygen activity at the different process steps BD, AD, DH02, BV and AV. Data are given for both the A heat and the B heats (B1-B5).

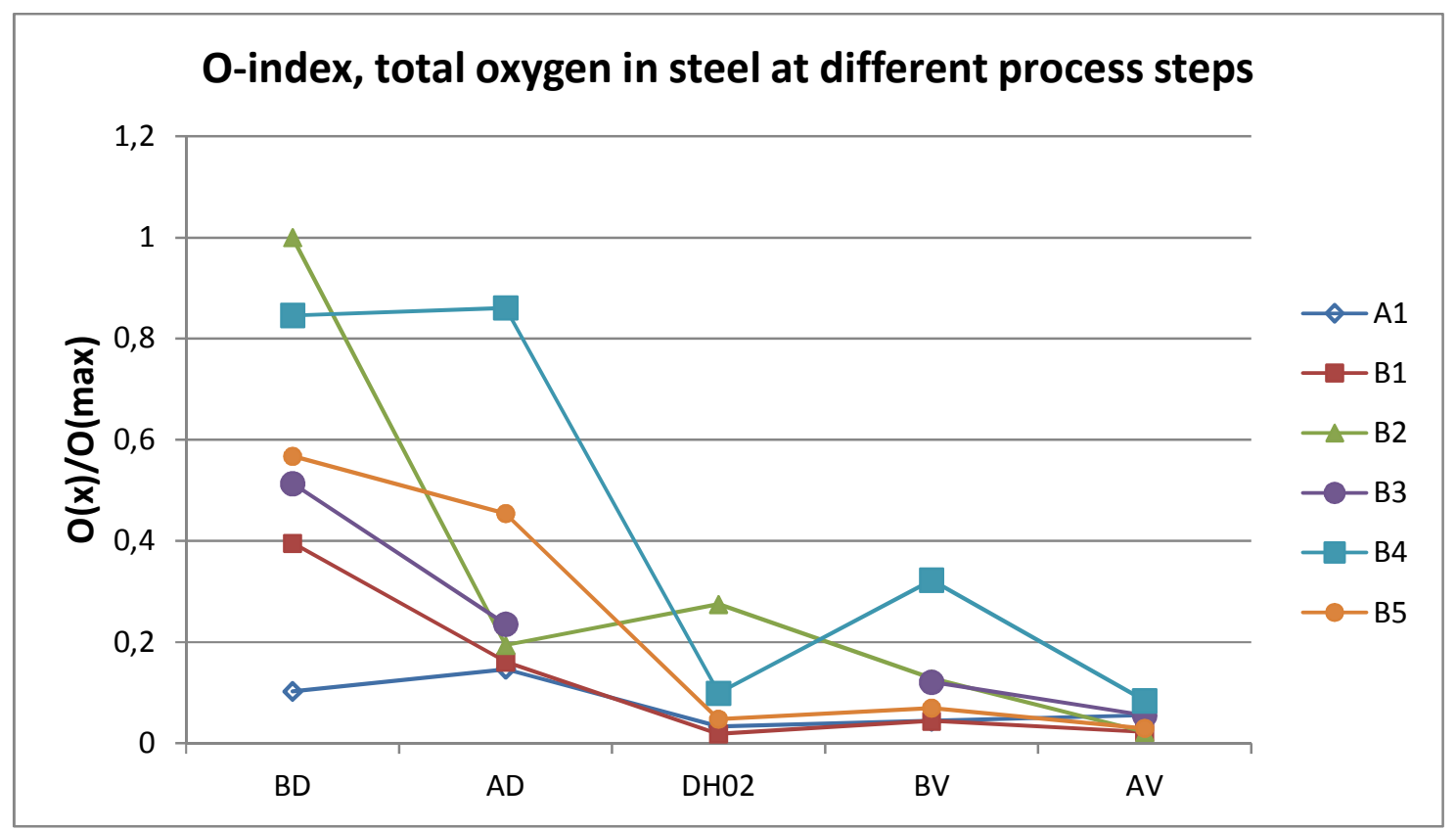

Figure 6. Total oxygen index at different process steps. Oxygen index $=($ total oxygen content at a specific time)/(maximum measured total oxygen content in this study). Data are given for both the A heat and the B heats (B1-B5). 


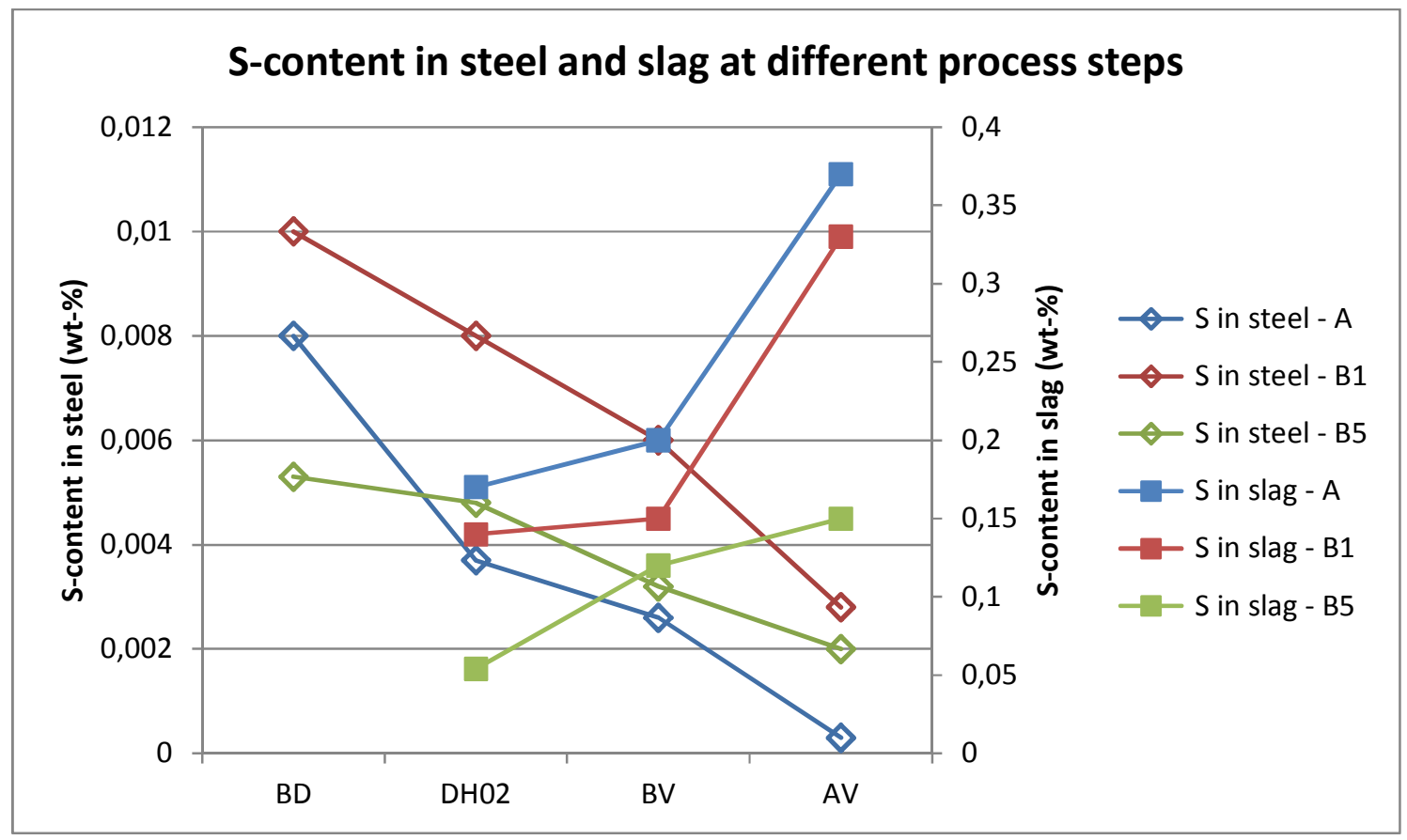

Figure 7. Sulphur content in steel and slag at different process steps for three heats.

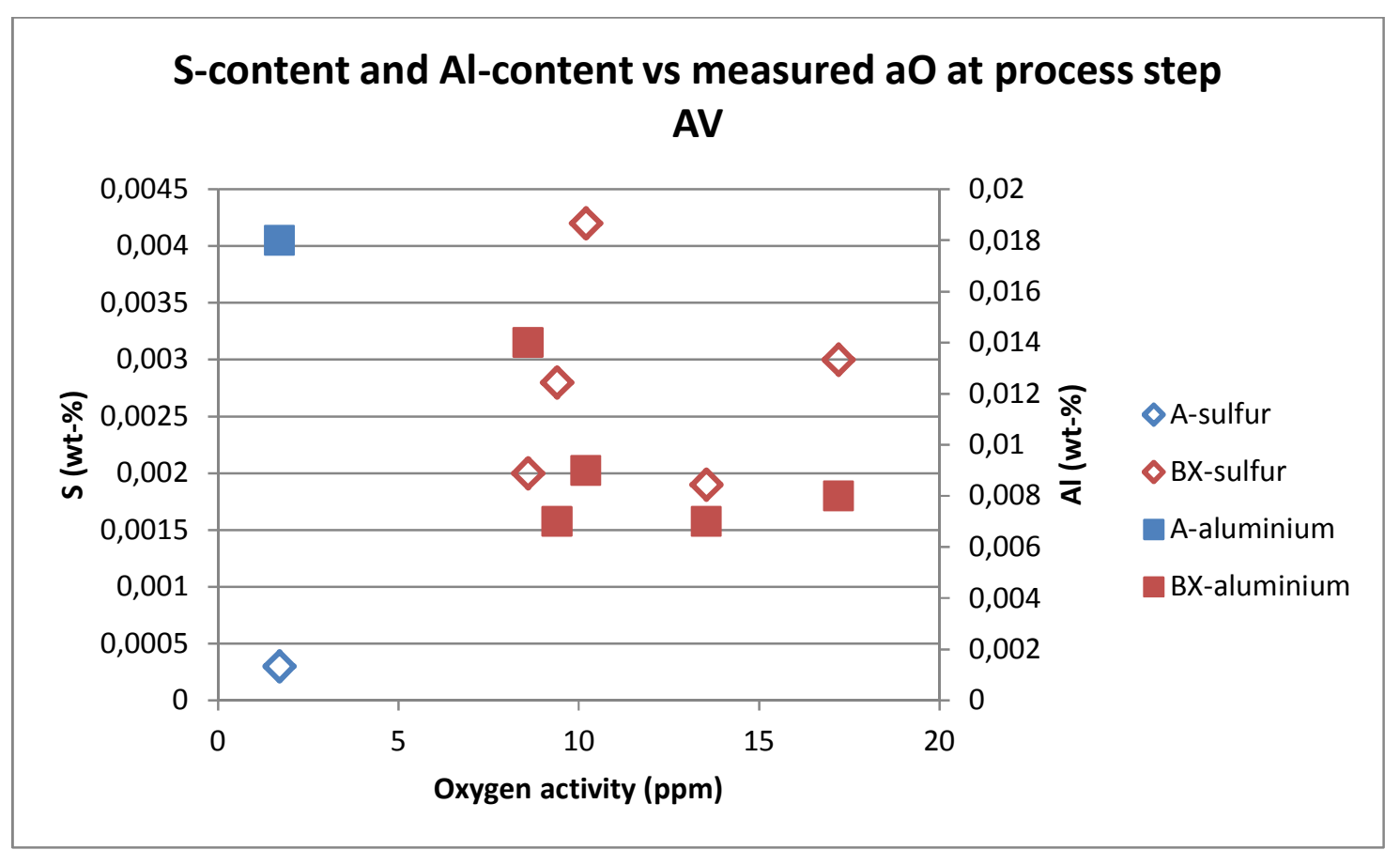

Figure 8. S- and Al-content in steel vs measured oxygen activity at process step AV for the different steel grades (A, B). 


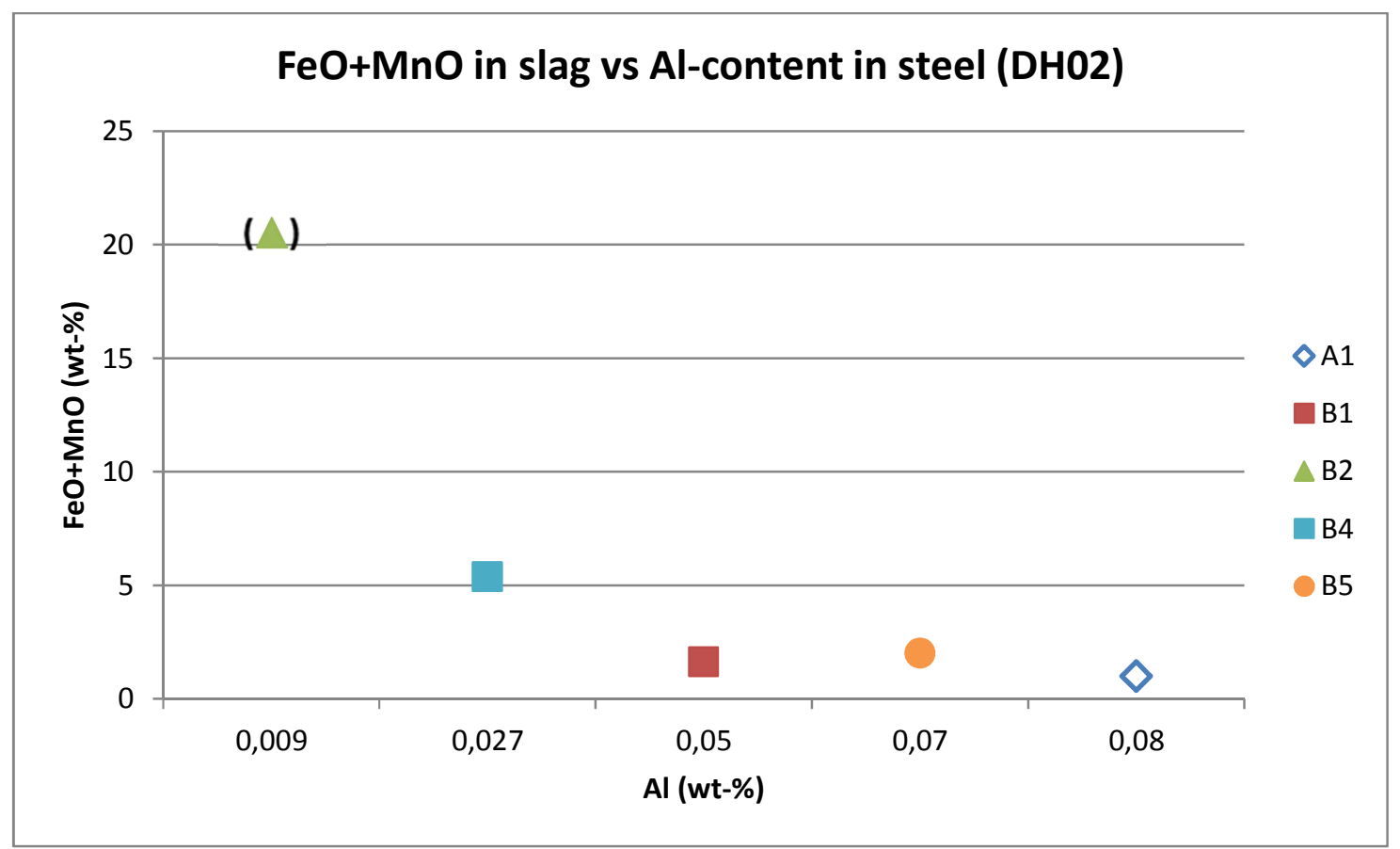

Figure 9. $\mathrm{FeO}+\mathrm{MnO}$ in slag vs Al-content in steel at process step DH02. Data are given for both the A heat and the B heats (B1-B5).

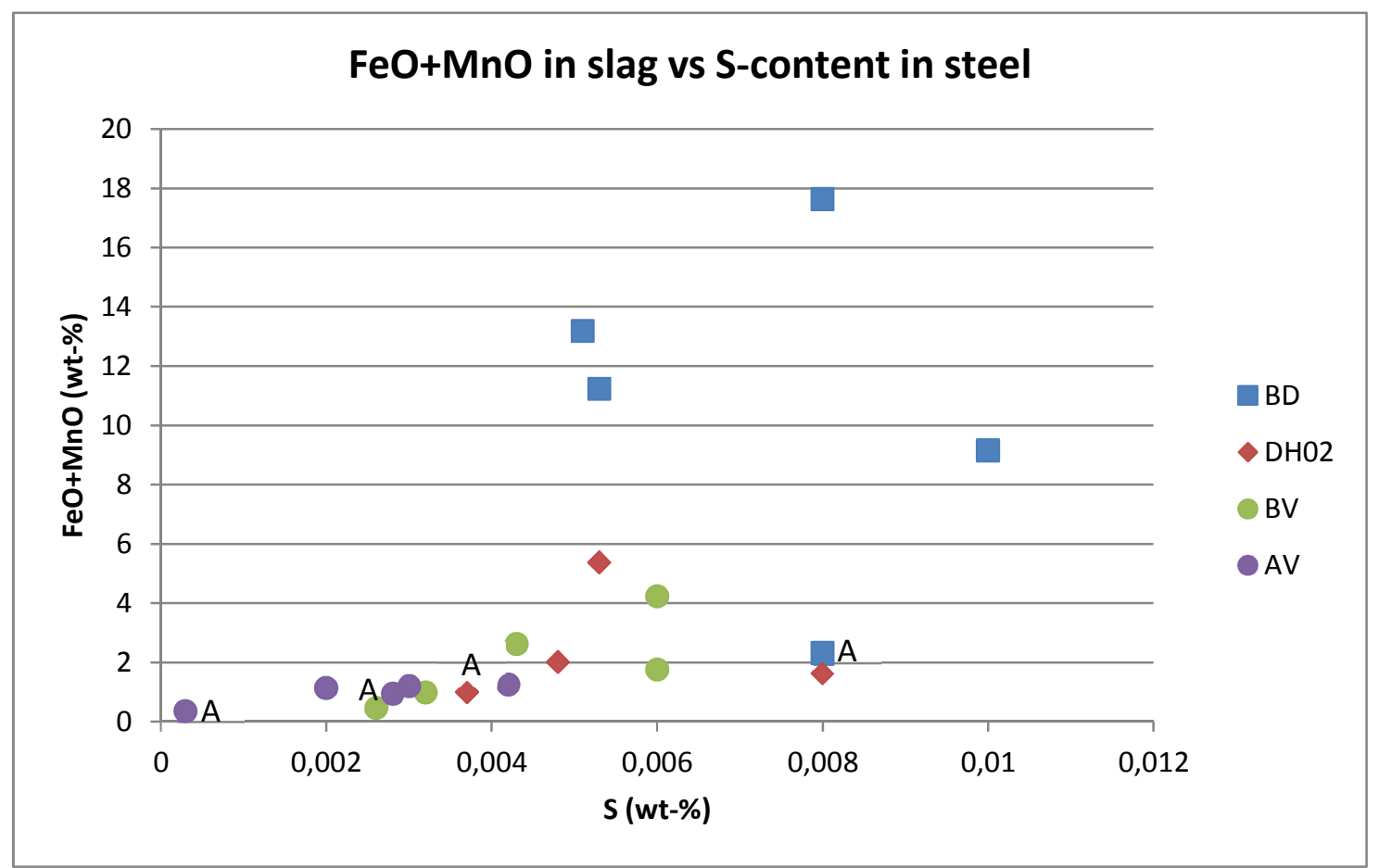

Figure 10. $\mathrm{FeO}+\mathrm{MnO}$ in slag vs S-content in steel at the different process steps BD, DHO2, BV and AV as well as for both the A heat and the B heats (B1-B5).

Points representing heat $\mathrm{A}$ has been marked to differentiate from the B-heats. 


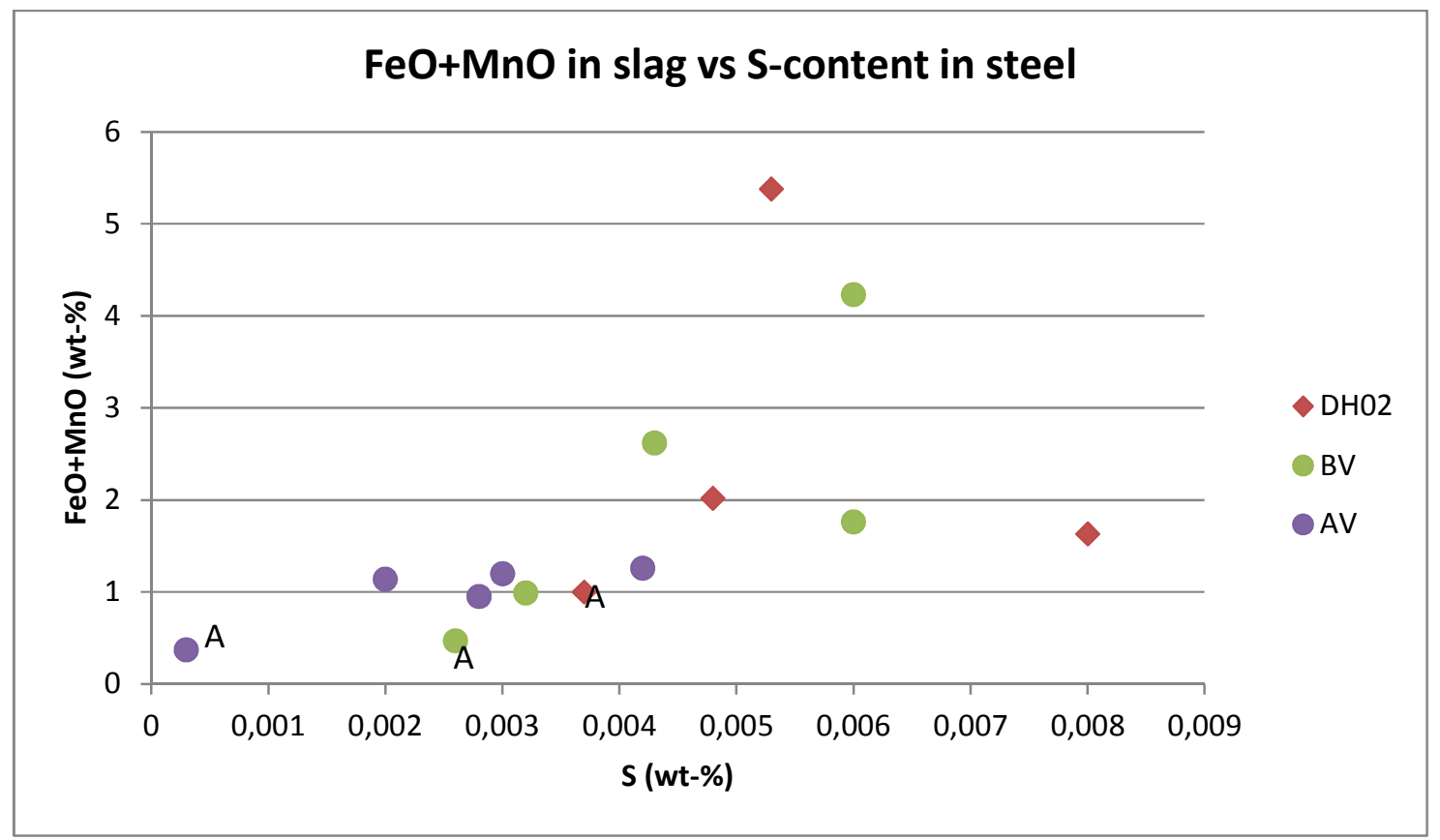

Figure 11. FeO+MnO in slag vs S-content in steel at the different process steps BD, $\mathrm{DHO} 2, \mathrm{BV}$ and AV, after that deslagging has been made and a new synthetic slag has been added. Data are given for both the A heat and the B heats (B1-B5). Points representing heat $\mathrm{A}$ has been marked to differentiate from the B-heats.

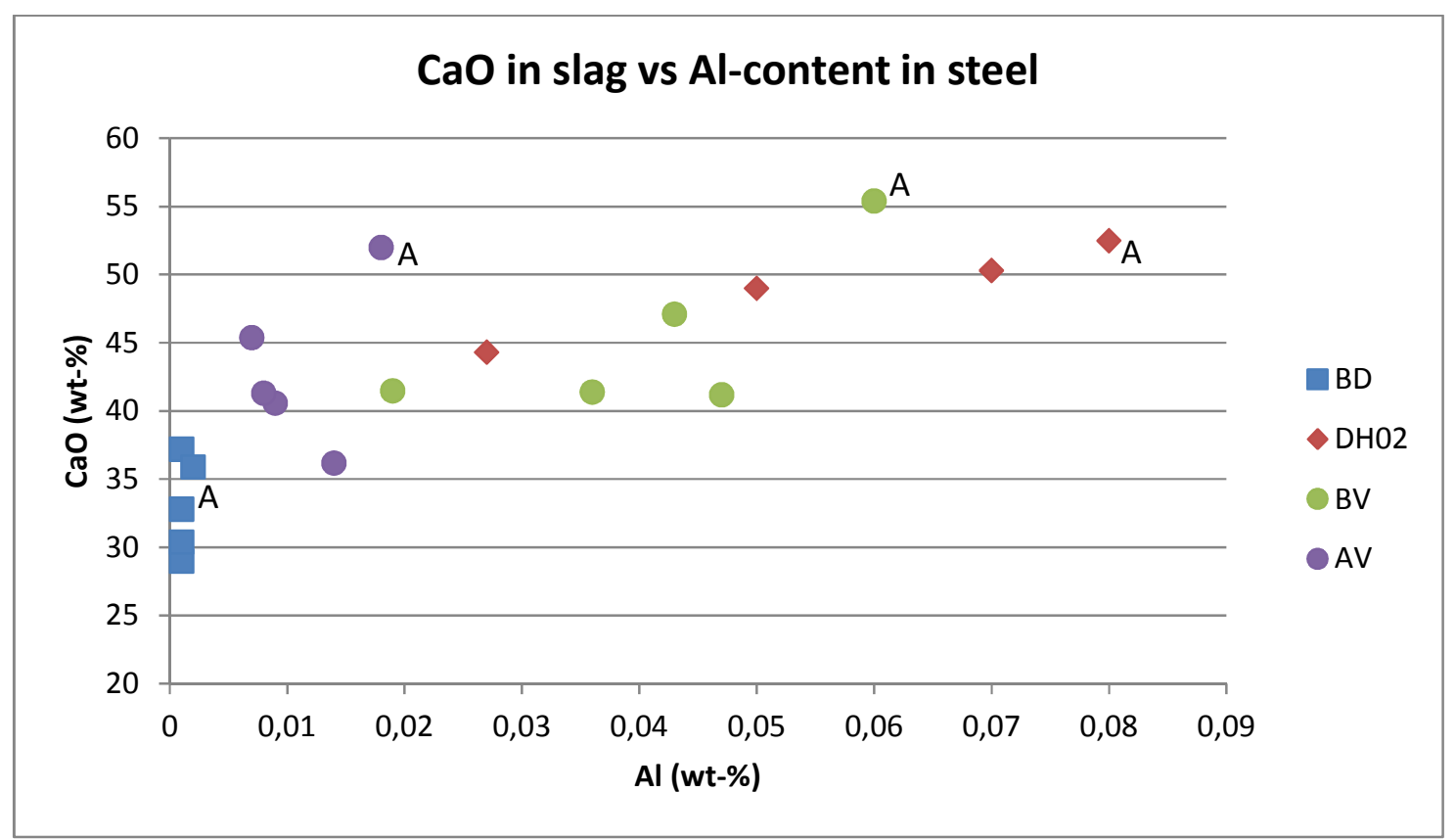

Figure 12. $\mathrm{CaO}$ content in the slag as a function of the $\mathrm{Al}$ content in the steel at the different process steps $\mathrm{BD}, \mathrm{DHO} 2, \mathrm{BV}$ and $\mathrm{AV}$ as well as for both the $\mathrm{A}$ heat and the $\mathrm{B}$ heats (B1-B5). Points representing heat A has been marked to differentiate from the Bheats. 


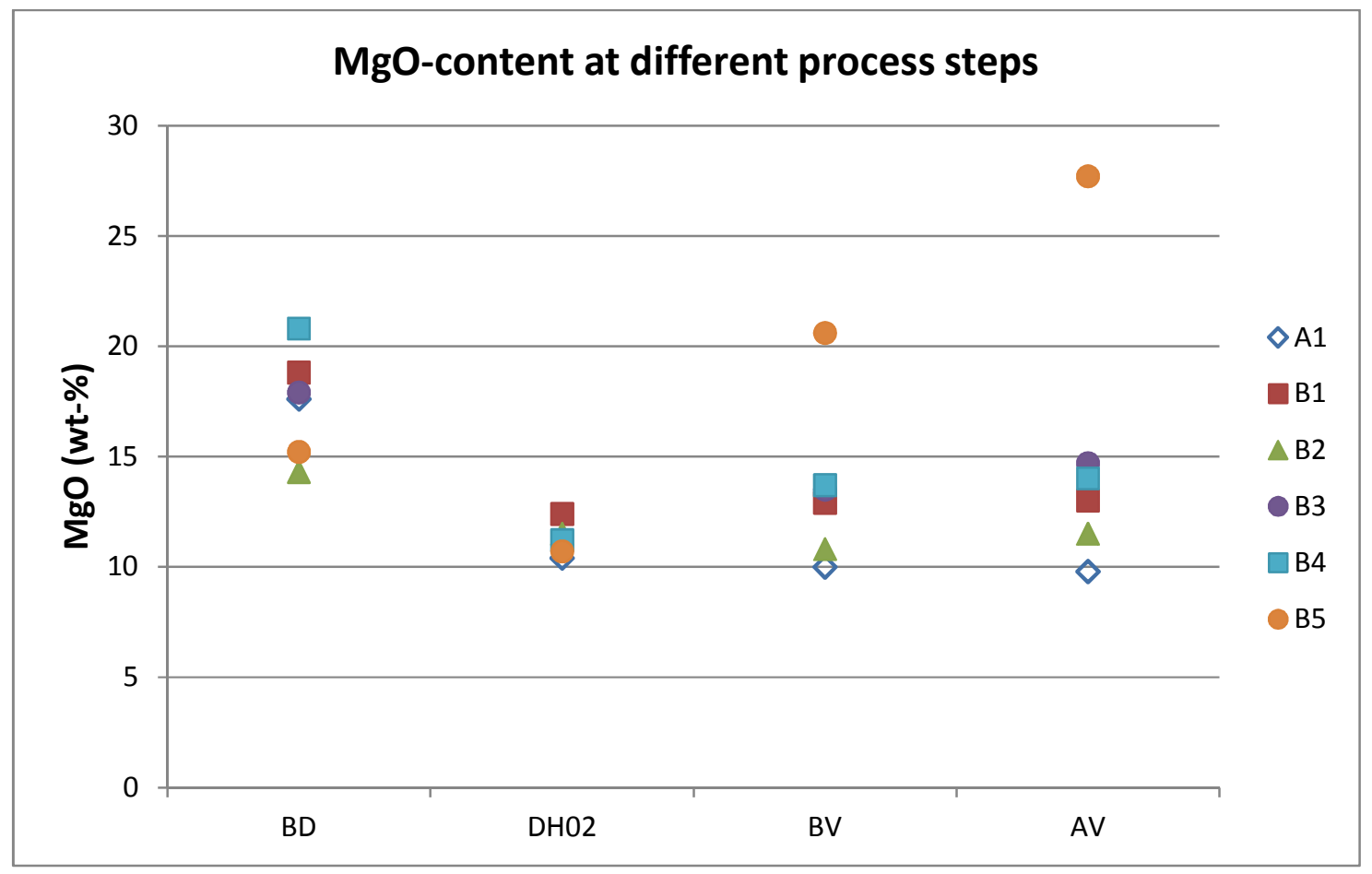

Figure 13. $\mathrm{MgO}$ content in slag at different process steps $\mathrm{BD}, \mathrm{DHO} 2, \mathrm{BV}$ and $\mathrm{AV}$ as well as for both the A heat and the B heats (B1-B5).

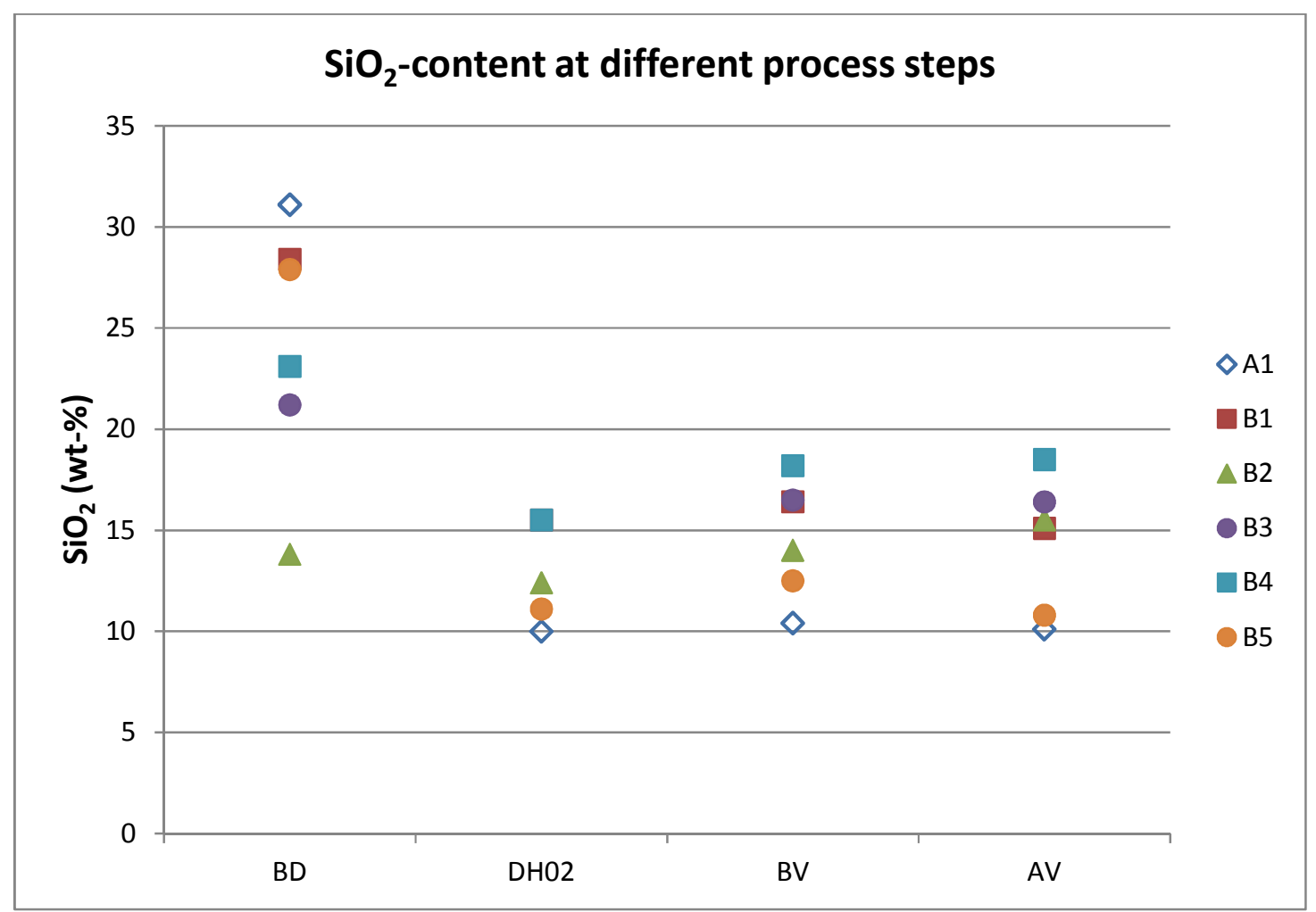

Figure 14. $\mathrm{SiO}_{2}$ content in slag at the different process steps $\mathrm{BD}, \mathrm{DHO} 2, \mathrm{BV}$ and $\mathrm{AV}$ as well as for both the A heat and the B heats (B1-B5). 


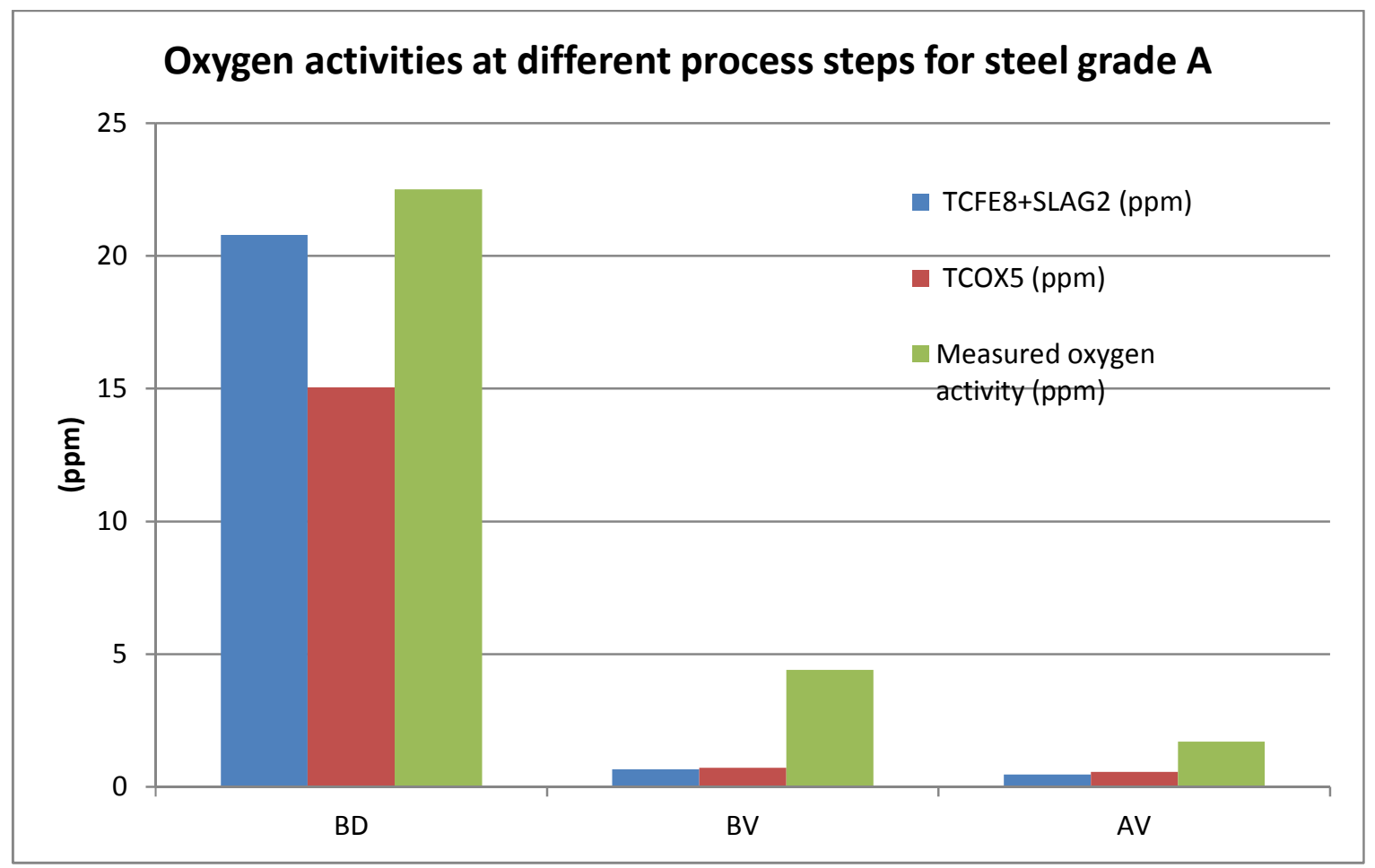

Figure 15. Oxygen activities at different process steps (BD, BV and AV) for steel grade A. Data are given for calculations using two data bases as well as for measurements.

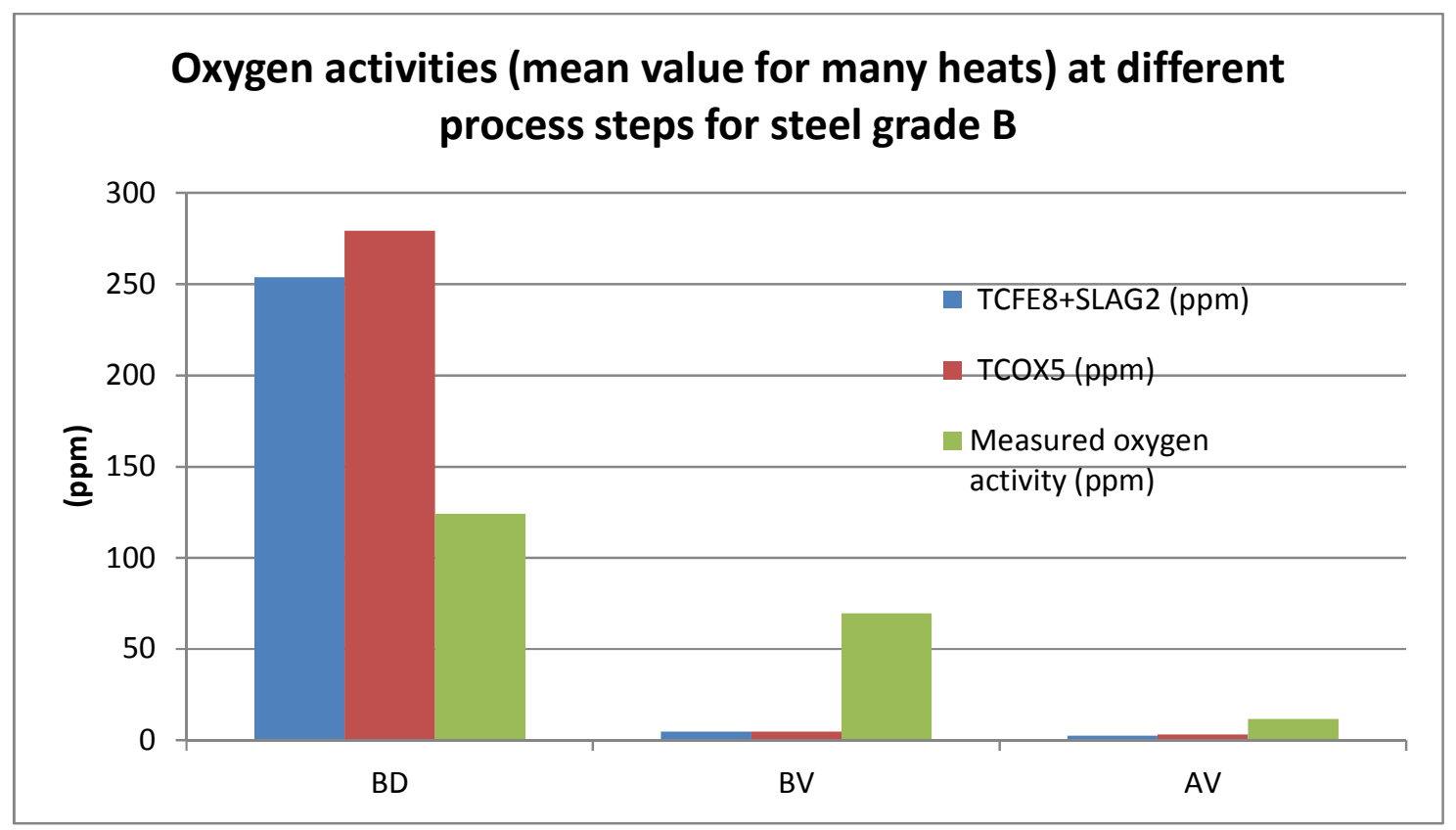

Figure 16. Oxygen activities at different process steps (BD, BV and AV) for steel grade B. Data are given for calculations using two data bases as well as for measurements. 


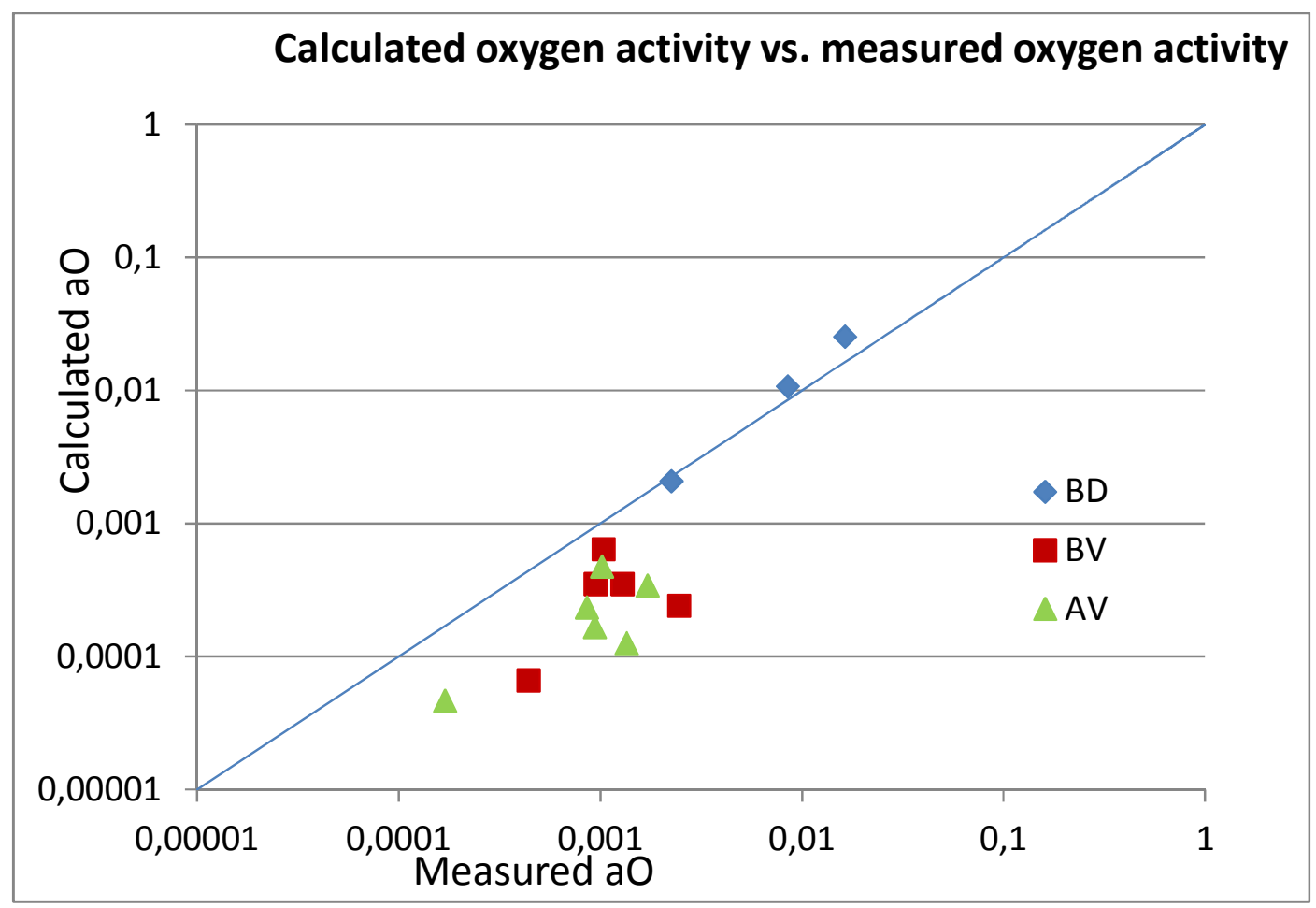

Figure 17. Calculated oxygen activity versus measured oxygen activity (Celox measurements) for the process steps $\mathrm{BD}, \mathrm{BV}$ and $\mathrm{AV}$.

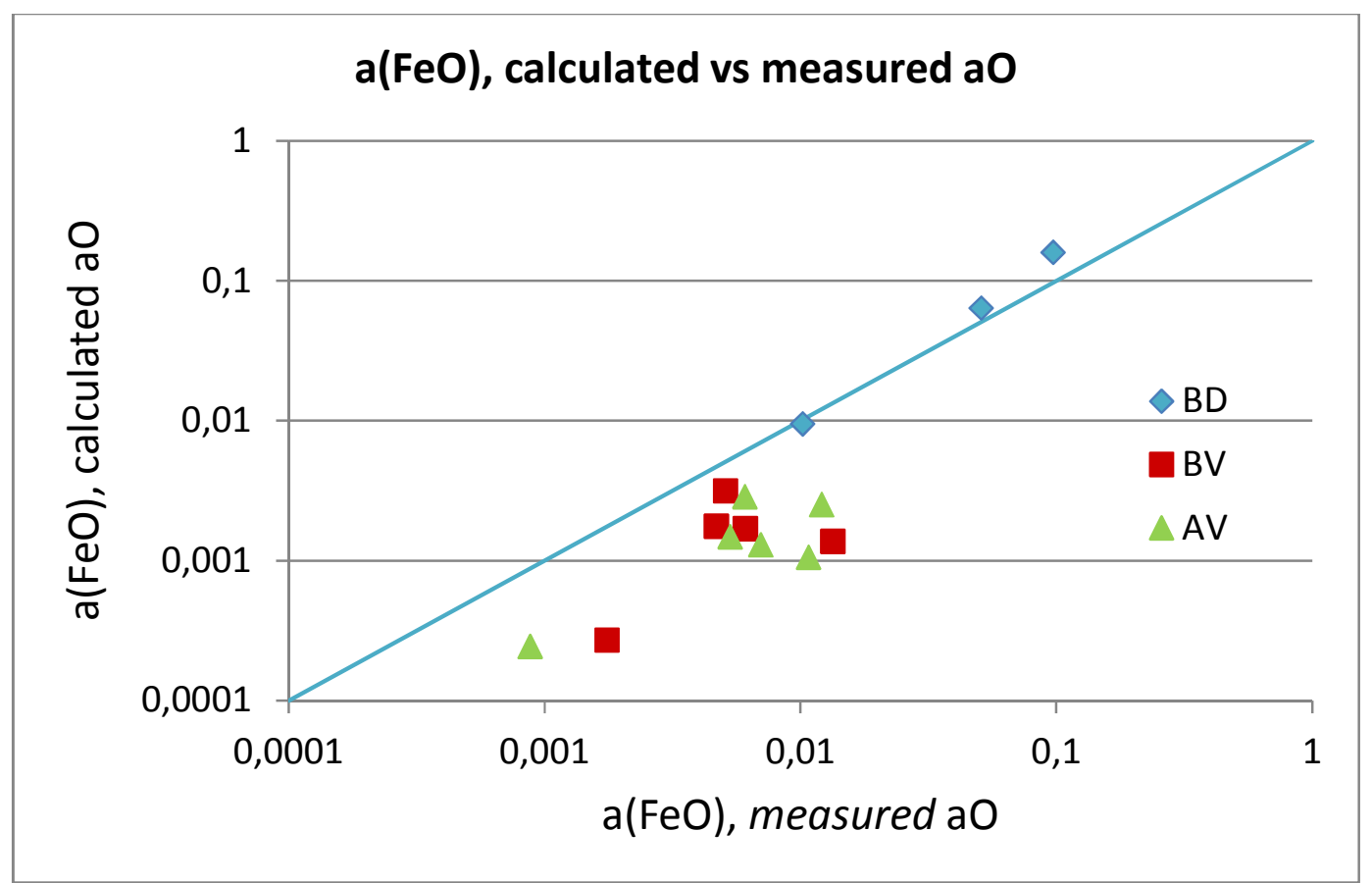

Figure 18. Activity of $\mathrm{FeO}$ in liquid slag based on calculated $\mathrm{a}_{\mathrm{O}}$ values as a function of a the activity of $\mathrm{FeO}$ in liquid slag based on measured $\mathrm{a}_{\mathrm{O}}$ values. Data are given for the process steps $\mathrm{BD}, \mathrm{BV}$ and $\mathrm{AV}$ 